NBER WORKING PAPER SERIES

DOES MONETARY POLICY MATTER? A NEW TEST IN THE SPIRIT OF FRIEDMAN AND SCHWARTZ

Christina Romer

David Romer

Working Paper No. 2966

NATIONAL BUREAU OF ECONOMIC RESEARCH

1050 Massachusetts Avenue

Cambridge, MA 0218

May 1989

This paper is part of NBER's research programs in Economic Fluctuations and Financial Markets and Monetary Economics. We have benefited greatly from the excellent comments and suggestions that we have received from numerous colleagues. We wish to thank particularly George Akerlof, Laurence Ball, Ben Bernanke, Olivier Blanchard, Charles Calomiris, Barry Eichengreen, Stanley Fischer, Benjamin Friedman, Milton Friedman, N. Gregory Mankiw, Thomas Mayer, Jeffrey Miron, Anna Schwartz, Richard Sutch, Peter Temin, and Janet Yellen. We are also grateful to the National Science foundation for financial support and to David Parsley for able research assistance. Any opinions expressed are those of the authors not those of the National Bureau of Economic Research. 
NBER Working Paper \#2966

May 1989

\section{DOES MONETARY POLICY MATTER? A NEW TEST IN THE SPIRIT OF FRIEDMAN AND SCHWARTZ}

\section{ABSTRACT}

This paper uses the historical record to isolate episodes in which there were large monetary disturbances not caused by output fluctuations. It then tests whether these monetary changes have important real effects. The central part of the paper is a study of postwar U.S. monetary history. We identify six episodes in which the Eederal Reserve in effect decided to attempt to create a recession to reduce inflation. We find that a shift to anti-inflationary policy led, on average, to a rise in the unemployment rate of two percentage points, and that this effect is highly statistically significant and robust to a variety of changes in specification.

We reach three other major conclusions. First, the real effects of these monetary disturbances are highly persistent. Second, the six shocks that we identify account for a considerable fraction of postwar economic fluctuations. And third, evidence from the interwar era also suggests that monetary disturbances have large real effects.

Christina D. Romer

David H. Romer

Department of Economics

University of California

Berkeley, CA 94720 


\section{INIRODJCTION}

This paper investigates whether nominal disturbances have important real effects. What differentiates the paper from the countless others on the same subject is that it focuses not on purely statistical evidence but on evidence derived from the historical record -- evidence based on what we call the "narrative approach." This approach was pioneered by Friedman and Schwartz in their Monetary History of the United States and has provided the evidence that we suspect has been most important in shaping economists' beliefs about the real effects of monetary shocks. Despite its significance, however, the narrative approach has been largely neglected in formal research in the twenty-five years since Friedman and Schwartz's work. In this paper we both assess the evidence presented in the Monetary History and, more importantly, conduct a test of the link between monetary disturbances and real output for the postwar United States in the spirit of Friedman and Schwartz's approach.

The reason that purely statistical tests, such as regressions of output on money, studies of the effects of "anticipated" and "unanticipated" money, and vector autoregressions, probably have not played a crucial role in forming most economists' views about the real effects of monetary disturbances is that such procedures cannot persuasively identify the direction of causation. On the one hand, if firms that are planning to expand their output first increase their demands for liquid assets (or for loans from commercial banks), money could rise before output rises even though money had no causal role (King and Plosser, 1984; Tobin, 1965). On the other hand, if the Federal Reserve were actively using monetary policy to offset the effects of other factors acting to change output, there might be no discernible relation between money and output even though money had large real effects (Kareken and Solow, 1963).

The Narrative Approach. The approach that we suspect in fact underlies most economists' beliefs concerning whether nominal disturbances matter is quite different from any purely statistical approach. We call it the narrative approach because its central element is the identification of "monetary shocks" through non-statistical procedures. Whether carried out systematically or casually, the method involves using the historical record, such as the descriptions of the process and reasoning that led to decisions by the monetary authority and accounts of the sources of monetary 
disturbances, to identify episodes when there were large shifts in monetary policy or in the behavior of the monetary sector that were not driven by developments on the real side of the economy. The test of whether monetary disturbances matter is then simply to see whether output is unusually low following negative shocks of this type and unusually high following positive shocks.

In their Monetary History, Friedman and Schwartz argue that the study of U.S. monetary history does indeed provide clear examples of large, independent monetary disturbances. They argue further that economic developments subsequent to the disturbances they identify provide overwhelming evidence that monetary shocks have large real effects. Evidence of the same kind, gathered and analyzed less systematically than that presented by Friedman and Schwartz, is also often cited in support of the view that monetary policy matters. References to the nolcker deflation" represent a common example of this type of argument. It is frequently argued that the fact that the commitment by the Federal Reserve in 1979 to a highly contractionary monetary policy to reduce inflation was followed by the most severe recession in postwar U.S. history provides powerful evidence of the real effects of monetary policy. Both this casual analysis and the more systematic analysis of Friedman and Schwartz have probably been more persuasive than purely statistical studies because the isolation of shocks from the historical record can overcome the reverse causation problem that plagues any regression of output on money.'

While the narrative approach has many virtues, implementing it is not straightforward. There are two specific problems that must be addressed. The first and more important possible difficulty involves the isolation of monetary shocks. Inherently, there cannot be a completely mechanical rule for determining when the historical record indicates that a shock has occurred. Moreover, the identification of shocks generally occurs retrospectively, and thus the researcher may know the subsequent behavior of money and output. The fact that the selection of disturbances is judgmental and retrospective introduces the possibility that there may be an unconscious bias toward, for example, searching harder for negative monetary shocks in periods preceding sharp declines in money and output than in other periods. Such a bias could cause one to misclassify shocks and to conclude that monetary disturbances had real consequences when they had none.

The second potential difficulty arises in determining whether the shocks that are identified are followed by unusual output movements. 
Neither Friedman and Schwartz nor those who cite similar informal evidence in support of the importance of monetary disturbances test formally whether the behavior of output in the aftermath of the disturbances that they identify is in fact systematically unusual. Indeed, Friedman and Schwartz explicitly deny that monetary shocks have consistent and precise real consequences, arguing their effects occur with long and variable lags. Carried to an extreme, an absence of statistical tests and a belief in irregular and often quite long lags could render the hypothesis that monetary shocks have important real effects void of testable implications. More moderately, these factors could cause the strength and significance of the effect to be overstated, and could compound the effects of biases in the selection of shocks.

Overview. This discussion of the benefits and dangers of the narrative approach leads us to believe that to answer the question of whether nominal disturbances have real effects, the narrative approach should be used, but that it should be used carefully and systematically. That is the goal of this paper.

We pursue that goal in two ways. The first is by reexamining Friedman and Schwartz's evidence concerning the real effects of monetary policy, particularly their identification of monetary disturbances. Despite the immense importance of their work in forming economists' views concerning the real effects of monetary forces, little research has been devoted to the question of how successful Friedman and Schwartz in fact are in isolating independent monetary disturbances. In section 2 we therefore investigate whether there appears to be any unintended bias in Friedman and Schwartz's choices of monetary shocks. ${ }^{2}$ We also use this critical analysis of the Monetary History to suggest improvements to Friedman and Schwartz's techniques.

The second and more important way in which we pursue the narrative approach is by proposing and implementing a test using this approach for the postwar United States. Friedman and Schwartz, writing in the early 1960s, necessarily focused on the period before World War II. We argue, however, that the postwar era provides a better setting for employing their approach. In particular, we argue that it is possible to come much closer in the postwar than in the prewar or interwar periods to the ideal of using a precise and unambiguous rule for identifying a central set of major monetary disturbances. Thus we believe that the postwar era provides not just 
additional, but superior evidence concerning whether nominal shocks matter. This new test is the subject of section 3. We describe the class of disturbances that we wish to identify, our procedures for identifying them, and our tests of whether the behavior of output in the wake of those disturbances provides evidence for or against the view that nominal disturbances have important real consequences.

Finally, in section 4 we return to the evidence from the interwar era. Having discussed in Section 2 whether Friedman and Schwartz's identification of monetary disturbances might involve some unintended bias, in this section we propose what we think is a more appropriate list of major independent monetary disturbances for the interwar period. Then, paralleling the test in section 3, we ask whether real activity responds systematically to those disturbances.

\section{FRIEDMAN AND SCHWARTZ CHAIIENGED}

The purpose of this section is to examine how successful and persuasive Friedman and Schwartz are in isolating independent monetary disturbances. We do this for two reasons. First, because the Monetary History has been so influential in shaping economists' beliefs, it is important to approach the work critically and to evaluate anew the quality of the evidence that it presents. Second, because the main purpose of our paper is to extend the narrative approach to the postwar era, it is useful to identify any potential shortcomings in Friedman and Schwartz's classic work so that we can avoid them in our own study of the historical record.

\subsection{Friedman and Schwartz's Major Monetary Shocks}

To set the stage, we begin by describing the episodes that Friedman and Schwartz identify as the most important monetary shocks during the period covered by the Monetary History. In keeping with the view that the most compelling evidence that Friedman and Schwartz provide of the importance of monetary shocks comes from the most dramatic events that they describe, we limit our attention to the episodes that they emphasize in their summaries of their work (1963a, ch. 13; 1963b, pp. 48-55); we do not consider the various more minor or less clear-cut episodes that they cite as providing further evidence of the importance of monetary disturbances. In addition, we limit ourselves to the shocks in the period after 1919. For the period before world war I, all of the shocks that Friedman and Schwartz 
emphasize are related to financial panics. We do not focus on the panics both because the degree to which panics represent independent monetary disturbances is a particularly complex issue and because Friedman and Schwartz place less emphasis on the panics than on the interwar shocks." with these restrictions, there remain four episodes in which Friedman and Schwartz identify major monetary shocks. Three of these episodes involve overt actions on the part of the Federal Reserve. In their chapter entitled "A Summing Up," Friedman and Schwartz state:

On three occasions the System deliberately took policy steps of major magnitude which cannot be regarded as necessary or inevitable economic consequences of contemporary changes in money income and prices. Like the crucial experiments of the physical scientist, the results are so consistent and sharp as to leave little doubt about their interpretation. The dates are January - June 1920, October 1931, and June 1936 - January 1937 (1963a, p. 688).

The fourth episode that Eriedman and Schwartz characterize as a major monetary shock is the Federal Reserve's inaction in the face of the severe economic downturn of 1929-31. They describe the events of this period as representing "a fourth crucial experiment" (1963a, p. 694).

Before we sketch Friedman and Schwartz's interpretations of these four episodes, it is useful to point out that by a monetary shock Friedman and Schwartz do not mean a monetary movement entirely unrelated to underlying economic developments. Instead, what they mean by a monetary shock is a movement that is unusual given economic developments -- that is, a movement that would not have occurred in other periods or other circumstances given the pattern of real activity. For the four critical episodes described below, the unusual movements in money arose, in Friedman and Schwartz's view, from a conjunction of economic events, monetary institutions, and the doctrines and beliefs of the time and of the particular individuals determining policy.

January - June 1920. Despite high output, low unemployment, and considerable inflation, monetary policy remained loose in the aftermath of World war I. The major reasons for this monetary ease included a desire to avoid raising the costs to the Treasury of financing outstanding debt, a desire not to inflict capital losses on the purchasers of the final issue of war bonds, and a belief that persuasion rather than high interest rates should be used to discourage borrowing. Then, in November 1919 the Federal Reserve tightened policy somewhat, raising the discount rate from 4 to 4 3/4\%. In 1920 the Federal Reserve raised the discount rate two additional 
times, from $43 / 4$ to 68 in January and from 6 to 78 in June. According to Friedman and Schwartz, there were two central reasons for the adoption of this extraordinarily restrictive policy at a time when a downturn was in fact already beginning. The first was a concern with the system's own reserve position rather than with broader economic conditions. The second was the fact - hardly surprising, given the brief history of the system -that the Federal Reserve misunderstood the lags with which monetary policy affected the economy. As a result, the Federal system repeatedly tightened policy before previous restrictions had had a chance to have an impact. (1963a, pp. 221-39.)

October 1931. Britain's departure from the gold standard led to widespread fears that the United States would also leave gold, and thus to a vast gold outflow. The Federal Reserve responded by raising the discount rate from $11 / 2$ to $31 / 28$ in two steps in october 1931 . Friedman and Schwartz consider this restrictive policy highly unusual because the economy was so severely depressed in 1931 and its condition was continuing to deteriorate. (1963a, pp. 315-17, 380-84.)

June 1936 - January 1937. By 1935 banks had accumulated vast excess reserves. Federal Reserve officials believed that these excess reserves reflected a low demand for loans and that as a result open-market operations would for the most part simply alter the relative shares of excess reserves and government bonds in banks' portfolios. Motivated mainly by a desire to put the system in a position where it could use open-market operations to affect the economy in the future should it wish to do so, and partly by a wish to respond to the inflation and rapid output growth that had occurred since 1933, in 1936 and 1937 the Federal Reserve doubled reserve requirements in three steps. Friedman and Schwartz believe that the excess reserves were in fact a reflection of banks' desire for increased liquidity in the aftermath of the widespread banking panics of 1929-33. As a result, the increase in reserve requirements led to a massive contraction of lending as banks worked to restore their excess reserves. Thus, according to Friedman and Schwartz, the Federal Reserve inadvertently caused a major monetary contraction because it misunderstood the motives of bankers. Furthermore, they believe that the unfamiliarity of reserve requirements as a policy instrument (the system had been granted authority to vary reserve requirements only in 1933) led to an unintentionally large shift in policy, 
and that the discreteness of the policy shift made reversal politically difficult. (1963a, pp. 449-62, 575-45.)

The early stages of the Great Depression. Friedman and Schwartz argue that, beginning most likely with the evidence of a severe downturn in the spring of 1930 and certainly by the time of the first wave of banking failures in late 1930, similar economic developments would not have led to such large declines in the money stock under the National Banking system, under the Federal Reserve in the 1910s and 1920s, or under the Federal Reserve in the postwar era. They therefore conclude that despite the absence of any acts of commission on the part of the Federal Reserve, the large fall in money during the first year and a half of the Depression -before Britain's departure from the gold standard in September 1931 -represents a monetary shock. (1963a, pp. 308-16, 367-80, 691-94.)

\subsection{Is There Bias in Friedman and Schwartz's Selection of Monetary Shocks?}

Friedman and Schwartz's definition of what constitutes a monetary shock or a "crucial experiment" is not highly precise: an episode involves a monetary shock if monetary developments were highly unusual given all of the relevant developments on the real side of the economy. As a result, Friedman and Schwartz's judgment is central to their identification of shocks; they must weigh a broad range of factors and decide whether the evidence as a whole indicates that a shock occurred. There is therefore a potential for subtle biasing of the selection of shocks. If, for example, their hope was to find evidence of the importance of monetary forces, they may have had an unintentional tendency to search somewhat harder for negative monetary shocks in periods before large declines in economic activity than at other times.

In this section we argue that this danger is genuine. We suggest that there does appear to be some unintended bias in Friedman and Schwartz's choice of shocks. This conclusion is based both on an analysis of episodes that Friedman and schwartz do not identify as shocks and on the consistent presence of contractionary non-monetary forces in the shocks that they do identify.

Candidate Episodes Not Included by Friedman and Schwartz. Suppose that Friedman and Schwartz had a tendency to search more carefully for "exogenous" negative monetary shocks before times of large falls in output 
than at other times. One would then expect there to be events Friedman and Schwartz did not include in their list of independent negative monetary disturbances that it is reasonable to think that they would have included had those events been followed by significant declines in output. We believe that there are two such episodes in the interwar period.

1933. A massive wave of banking failures began in the final months of 1932 and worsened in early 1933. In addition, expectations of that Roosevelt might devalue or abandon the gold standard on taking office caused large gold outflows and led to an increase in the discount rate from $21 / 2$ to $31 / 28$ in February to defend gold. By February banking conditions had degenerated into panic, causing widespread bank failures. The failures were in turn followed by the declaration of bank holidays in many states. On his inauguration in March, Roosevelt imposed a nationwide banking holiday -- a step that, in Friedman and Schwartz's view, was extraordinarily disruptive of the financial system and much more drastic than was needed. (Friedman and Schwartz, 1963a, pp. 324-32, 349-50, 389-91, 421-34.)

The events of these months have the features of what under different circumstances Friedman and Schwartz would be willing to describe as a monetary shock, or indeed as several shocks. At other times widespread banking failures and panic conditions much milder than those of early 1933 are considered to be monetary disturbances. The gold outflow and the increase in the discount rate to defend the gold standard despite the depressed level of real activity clearly represent unusual monetary developments, similar to those of the fall of 1931. And the Bank Holiday shares with the episodes emphasized by Friedman and Schwartz the feature that one can argue that it represents a major contractionary step arising from an inadequate understanding of the workings of the financial system. In sum, it seems extremely plausible that if the depression had continued to worsen in 1933, Friedman and Schwartz would have characterized the events of January - March 1933 as a fifth "crucial experiment."

1941. In September 1941 the Federal Reserve announced a decision to raise reserve requirements from $221 / 2$ to $25 \%$ in November. The increase was the same size as each of the last two steps of the three-step increase in reserve requirements in 1936-37. This is important because it is these last two increases that Friedman and schwartz emphasize in analyzing 1937.

Furthermore, as Friedman and Schwartz note of the 1937 increases, the openmarket operations needed to create a comparable reduction in excess reserves 
would have been extraordinarily large (1963a, pp. 531-32). But they attach little importance to the 1941 increase. They simply state that:

[banks] made no attempt to rebuild their excess reserves, as they had after the increases of 1936 and 1937, but rather proceeded to continue to reduce their remaining excess reserves. The effect of the reserve requirement increase shows up only in a slackened rate of rise of the deposit-reserve ratio ... (p. 556).

The striking contrast between Friedman and Schwartz's interpretations of the reserve requirement increases of $1936-37$ and 1941 suggests that they commit the natural error of using the subsequent behavior of money as a critical factor in identifying monetary disturbances. This is inappropriate because the central reason for employing the narrative approach is that monetary changes may be partly endogenous. And if money is in part governed by output, money could have risen even after a contractionary monetary. shock, because non-monetary factors were clearly expansionary in 1941 . If the 1941 increase in reserve requirements had been followed by falls in the deposit-reserve ratio and in money, it appears plausible that Friedman and Schwartz would have described the action as a monetary shock. Because the Federal Reserve remained unfamiliar with changes in reserve requirements, Friedman and Schwartz could reasonably have argued that the system again committed the error of causing a drastic shift in policy when only a modest one was intended."

The Episodes Included by Friedman and Schwartz. A second argument that there appears to be some bias in Friedman and Schwartz's identification of monetary shocks focuses on the episodes that they do select. If their selections are unbiased, the effects of non-monetary factors will not be systematically different following the monetary episodes identified than they are at other times. If the selections are biased, on the other hand, there will be a tendency for episodes in which other factors were acting to increase output to be excluded from a list of negative monetary disturbances and for episodes in which other forces are acting to reduce output to be included. We argue that in all of the episodes identified by Friedman and Schwartz as involving independent negative monetary shocks (with the possible exception of the period following Britain's departure from gold in 1931), non-monetary forces appear to have been strongly contractionary.

January - June 1920. It is not difficult to find candidate nonmonetary explanations of the decline in output from 1919 to 1921 . With the 
end of World war $I$ and the large-scale immediate postwar relief efforts, government spending fell sharply. In addition, it is often argued that the postponement of purchases of durable goods during the war contributed to the high level of demand in 1919 and the subsequent fall in 1920-21 (Gordon, 1974, pp. 19-20, for example). Indeed, Friedman and Schwartz agree that non-monetary forces contributed to the downturn and may have made it inevitable (1963a, p. 237).

Two comparisons suggest that non-monetary forces were important in 1920-21. The first comparison is with other countries. Declining output was not unique to the United States. In 1919-21, there were falls in output much larger than that in the United States in the United Kingdom, Italy, Norway, and Canada (Maddison, 1982, Table A7). The breadth of the downturn suggests that the contractionary forces were broader than the idiosyncracies of U.S. monetary policy. The second comparison is with the aftermath of World War II. From 1918 to 1921, government purchases as a fraction of GNP fell by 13 percentage points; real GNP rose 1.18 from 1918 to 1919 and then fell 3.58 between 1919 and 1921." From 1944 to 1947, the share of government purchases in GNP fell by 35 percentage points; real GNP fell by 25.88. That is, the fall in total output relative to the fall in government purchases was considerably larger after World War II than after World War I.' This comparison suggests that in isolation the decline in government spending between 1919 and 1921 may have been depressing the economy greatly.

October 1931. We view the Federal Reserve's response to Britain's departure from gold as perhaps Friedman and Schwartz's clearest example of a monetary disturbance not obviously complicated by strongly contractionary non-monetary forces. Nonetheless, two non-monetary forces do appear to have been acting to reduce output after october 1931. First, fiscal policy turned contractionary, though less sharply than in 1918-20. The enactment of a massive tax increase in 1932 reduced $E$. Cary Brown's measure of the full employment deficit from 3.68 of GNP in 1931 to 1.88 in 1932 and then to 0.58 in 1933 (Brown, 1956, Table 1, col. 14). Second, it was during the period 1930-32 that the erection of massive tariff barriers and the consequent collapse of world trade reached its height, a development often thought to be central to the deepening of the depression (Kindleberger, 1986, pp. 123-26).

June 1936 - January 1937. Two non-monetary forces were acting to decrease output in 1937. The first was fiscal policy. From 1936 to 1937 
Brown's measure of the full employment deficit moved toward surplus by $2.4 \%$ of GNP, reflecting the end of the 1936 veterans' bonus and the first widespread collection of social security payroll taxes. The second was labor market developments. The enactment of the wagner Act in 1935 led, in a common interpretation, to large inventory accumulation in anticipation of labor market strife and wage increases; both the end of the inventory accumulation and the appearance of the anticipated strikes and wage increases then contributed to the downturn in 1937 (Kindleberger, pp. 27071). Over half of the fall in real GNP from 1936 to 1937 took the form of a sharp reversal of inventory investment.

In addition, it is essential to Friedman and Schwartz's interpretation of economic developments in this period that banks strongly desired to hold large excess reserves and that they therefore responded to the increase in reserve requirements by moving to restore their excess reserves. But the behavior of reserve holdings appears strikingly counter to this interpretation: there was no discernible change in the behavior of reserves as a fraction of deposits until December 1937, seventeen months after the first increase in reserve requirements was announced. By this time the declines in money and industrial production were largely complete.'

The early stages of the Great Depression. The issue of whether monetary or non-monetary forces were primarily responsible for the initial two years or so of the collapse of economic activity that began in 1929 has been sufficiently debated that there is no need for us to argue that the case in favor of a monetary interpretation is not clear-cut. As in the other episodes we have discussed, non-monetary forces were strongly contractionary during this period (see Temin, 1976, and Romer, 1988b). Indeed, Friedman and Schwartz do not argue that monetary policy lor some other aspect of monetary developments) was unusually contractionary from the stock market crash in october 1929 through the spring of 1930 , a period that saw industrial production fall by 13\%. Moreover, from the spring through October 1930, when industrial production fell an additional $16 \%$, according to Friedman and Schwartz monetary developments were unusual in at most a passive sense -- monetary authorities failed to intervene in the way that they normally would have in such a crisis. This view appears to imply that although monetary forces played a role, the initiating shocks during this period were not monetary. And indeed, as has been extensively discussed, the behavior of interest rates appears more consistent with the non-monetary 
than the monetary interpretation of the initial downturn (Temin, 1976;

Hamilton, 1987). In addition, by late 1930 there were additional nonmonetary forces at work: the collapse of world trade (discussed above) and possible non-monetary effects of bankruptcies and bank failures (Bernanke, $1983)$.

\subsection{Conclusion}

This discussion of possible bias in Friedman and Schwartz's identification of shocks is not meant to imply that the evidence from the interwar era is unsupportive of the view that monetary disturbances have important real consequences. It does, however, suggest that their evidence may not be as decisive as it once seemed. The fact that Friedman and Schwartz exclude some apparent negative shocks that were followed by improvements in economic performance, and the fact that the effects of the monetary shocks that they identify appear to have been compounded by adverse non-monetary factors, both imply that monetary shocks, by themselves, may be less potent than Friedman and Schwartz argued.

Our analysis of Friedman and Schwartz's identification of shocks also suggests an important lesson about using the narrative approach. The main reason that there is room for unconscious bias in Friedman and Schwartz's identification of shocks is that they use a very broad definition of what constitutes a shock: a shock occurs whenever monetary policy is "unusual" given the state of the real economy. Friedman and Schwartz are forced to adopt this definition because there is so much variation in monetary institutions, in the theoretical framework adhered to by central bankers, and in the particulars of important monetary episodes in the interwar era. Because of this variation, it is impossible to lay out a clear and workable set of criteria that can be used to identify monetary shocks throughout the interwar period. Therefore, an natural way to attempt to improve on what Friedman and Schwartz do is to apply the narrative approach to an era where a more precise definition of a shock can be specified.

\section{FRIEDMAN AND SCHWARTZ EXTENDED}

As a laboratory for a test of the real effects of monetary disturbances, the postwar era stands in admirable contrast to the interwar years. At least in comparison to the interwar era, the Federal Reserve in the postwar era has had a reasonably stable view of the functioning of the 
economy and of the role of monetary policy. As a result, there have been important similarities across major monetary episodes. Thus, while judgment still plays a role in the identification of shocks -- as it must do when identification is based on the historical record -- its role can be much smaller than in the earlier period. In addition, for the postwar period there are extensive contemporary records of the nature and motives of Federal Reserve policy. This is useful because reliance on contemporaneous judgments of the sources and intents of shifts in policy again reduces the scope for judgment and unconscious bias.

In this section we therefore use the narrative approach to study whether monetary policy shocks in the postwar era have had important real effects. The section is divided into two parts. Section 3.1 discusses our procedures for identifying monetary shocks in the postwar era and sketches the evidence underlying our choices of monetary shocks. Section 3.2 presents evidence on whether these monetary shocks affect output. It includes both informal evidence and a statistical test of whether the monetary disturbances we identify are followed by unusual movements in real output.

\subsection{The Identification of Monetary Shocks}

Definition. Like Friedman and Schwartz, we use the historical record to identify monetary shocks. We employ, however, a much narrower definition of what constitutes a shock. In particular, we count as a shock only episodes in which the Federal Reserve attempted to exert a contractionary influence on the economy in order to reduce inflation. That is, we focus on times when the Federal Reserve attempted not to offset perceived or prospective increases in aggregate demand but to actively shift the aggregate demand curve back in response to what it perceived to be "excessive" inflation. Or, to put it another way, we look for times when concern about the current level of inflation led the Federal Reserve to attempt to induce a recession (or at least a "growth recession").

This definition of a monetary shock is clearly very limited. It excludes both monetary contractions that are generated by concerns other than inflation and all monetary expansions. This single-minded focus on negative shocks to counteract inflation has two crucial advantages. Its most obvious advantage is that it defines a shock in narrow and concrete terms. Rather than looking for times when monetary policy was unusual given everything else that was going on in the economy, as Friedman and Schwartz 
do, we look only for times when the Federal Reserve specifically intended to use the tools that it had available to attempt to create a recession to cure inflation. This precise definition greatly limits the role of judgment in identifying monetary shocks.

The second reason for our limited focus is that we believe that policy decisions to attempt to cure inflation come as close as practically possible to being independent of factors that affect real output. In other words, we do not believe that the Federal Reserve states an intent to cause a recession to lower inflation only at times when a recession would occur in any event. This belief rests partly on an assumption that trend inflation by itself does not affect the dynamics of real output. We find this assumption reasonable: there appears to be no plausible channel other than policy through which trend inflation could cause large short-run output swings. By contrast, other factors that are important to the formation of monetary policy are likely to affect real activity directly. For example, because shifts to expansionary monetary policy in the postwar era almost always stem from a desire to halt declines in real output, these policy changes are obviously far from independent of factors that affect the path of output. As a result, it would be difficult to distinguish any real effects of expansionary shifts from whatever natural recovery mechanism the economy may have. It is for exactly this reason that we focus only on negative shocks.

Our belief that anti-inflationary shifts in policy are not simply occurring whenever a recession is about to occur also rests on a belief that the Federal Reserve is not always in fact reacting to some other factor -such as a large adverse supply shock or a temporary output boom -- that might by itself lead to a recession. As our descriptions of the specifics of the episodes that we consider will show, this does not appear to be the case. Indeed, as we describe, the inflation to which the Federal Reserve responds often appears to be the largely result of past shocks rather than of current real developments. Furthermore, in our statistical work below we attempt to test both for the possibility that anti-inflationary policy shifts are correlated with other factors that potentially affect real output and for the possibility that inflation directly affects real output. We find no evidence of either of these effects.

To actually discern the intentions of the Federal Reserve we rely entirely on contemporary Federal Reserve records -- the "Record of Policy Actions" of the Board of Governors and the Federal Open Market Committee 
(FOMC) and, until their discontinuance in 1976, the minutes of FOMC meetings. To identify a shock from these sources we look both for a clear statement of a belief that the current level of inflation needed to be lowered and some indication that output consequences would be sought, or at least tolerated, to bring the reduction about. In this process we only consider contemporaneous (or nearly contemporaneous) statements of the Federal Reserve's intent. We do not consider retrospective discussions of intent because such descriptions could be biased by a knowledge of the subsequent behavior of real activity.

Results. On the basis of Federal Reserve records, we identify six times since World War II when the Federal Reserve moved to attempt to induce a recession to reduce inflation. They are October 1947, September 1955. December 1968, April 1974, August 1978, and October 1979. In each case, the Federal Reserve appears to have made a deliberate decision to sacrifice real output to lower inflation. In this section we describe the evidence from contemporaneous Federal Reserve sources of shifts in the objectives of monetary policy during these episodes. In addition, to provide further information about our selection procedure, we describe two episodes that we do not classify as independent monetary disturbances. One occurred in 1966 when the system shifted to tighter policy out of a desire to prevent increases in aggregate demand rather than out of a desire to contract demand. The other occurred over the extended period 1975-78 when the Federal Reserve expressed considerable concern about inflation but did not appear to be willing to sacrifice real output to reduce it.

October 1947. With the end of world war II, inflation became the Federal Reserve's central concern. Two factors, however, stopped the Federal Reserve from shifting to significantly tighter policy in the first few years after the end of the war. The first was the wartime policy of pegging interest rates on both short-term and long-term government bonds. By June 1946 there was considerable sentiment on the FOMC in favor of pursuing policies that would cause short-term interest rates to rise (Minutes, 1946, pp. 55-56, for example). But obtaining a consensus in favor of such policies and then reaching an agreement with the Treasury to permit short-term rates to increase was a lengthy process; the pegging of shortterm interest rates did not end until July 1947. Second, although inflation was the primary concern, there was also fear that the end of the war would lead to renewed depression. 
In October 1947, with short-term interest rates no longer fixed and fears of depression allayed, the Federal Reserve began a series of contractionary measures. These actions included open-market operations designed to increase short-term interest rates, an increase in the discount rate, and an increase in reserve requirements for banks in central reserve cities. The motive behind these measures was a desire to reduce inflation. At the June 1947 FOMC meeting,

it was [the] opinion [of the chief Federal Reserve economist present] that throughout the war and postwar period there had been too many fears of postwar deflation, with the result that actions which should have been taken to counteract inflation were not taken, because of the fear that they would result in contraction, and that, although any downturn should be taken care of at the proper time, the important thing at the moment was to stop abnormal pressures on the inflationary side. (Minutes, 1947 , p. 111.)

He held this view even though he believed that economic conditions were not strengthening. The views of the other Board economist present were summarized succinctly: "He thought that there would and should be a mild recession" (Minutes, 1947, p. 112). In sum, beginning in late 1947 the Federal Reserve was actively attempting to reduce aggregate demand in order to reduce inflation.

September 1955. Beginning in roughly June 1954, in response to evidence of the end of the 1953-54 recession, the Federal Reserve ceased pursuing what it perceived to be an actively expansionary policy. This change, of course, does not represent a monetary shock. The Federal Reserve was not attempting to reduce aggregate demand; rather, it simply believed that active stimulus was no longer needed for output to grow.

Beginning in early 1955 considerable concern was expressed by the Federal Reserve about inflation.' This concern does not seem to have had an important effect on policy during the first part of the year. But in approximately september 1955 the character of policy appears to have changed. The Federal Reserve actively began to attempt to contract aggregate demand even though members of the FOMC did not believe that output growth, or expected future output growth, was stronger than before. At the FOMC meeting of September 14, for example, despite the fact that "review of the available data suggested that the economy had entered a phase of decelerating advance, ... it was the judgment of the committee that [the] situation called at least for the maintenance of, and preferably some slight 
increase in, the restraining pressure it had been exerting through open market operations." The reason was that "price advances were occurring in considerable numbers, with further widespread increases in prospect" (both quotations are from 1955 Annual Report, p. 105). In October they suggested that a mild downturn might not be undesirable: "the Committee concluded the situation called for continuing the present policy of restraint" despite the fact that a "tendency toward a downturn in the economy ... might develop" (1955 Annual Report, p. 106). In November the Committee wished to dispel "any idea of an easing of System policy" (1955 Annual Report, p. 108; emphasis added).

The Federal Reserve's conduct in the first part of 1956 lends additional support to the view that system policy shifted in the fall of 1955. During this period the FOMC felt that no change in policy was called for in the face of evidence of essentially zero output growth. This indicates that expansion at less than trend rates was what they were seeking. ${ }^{30}$ In March the Committee explicitly took the view that it should "combat an inflationary cost-price spiral" despite "the risk of incurring temporary unemployment" (1956 Annual Report, p. 26). We conclude that the Federal Reserve shifted to a policy of actively attempting to reduce aggregate demand to combat inflation in late 1955.

1966. Despite its fame, the "credit crunch" of 1966 does not represent a monetary shock by our criteria. The reason is that the Federal Reserve's stated intent was clearly not to reduce aggregate demand, but rather to prevent outward shifts in aggregate demand that it believed would otherwise have occurred. In December 1965, for example, the system raised the discount rate and acted to increase other interest rates in response to evidence that "economic activity was increasing vigorously and that the outlook appeared more expansive than previously, "not out of a desire to induce a contraction (1965 Annual Report, p. 150). The perception of the economy's strength was based not just on current data but also on projections of growing military expenditures because of the Vietnam war and survey evidence that consumers and firms were planning to increase their spending. The Federal Reserve stated explicitly that the purpose of the shift in policy "was not to cut back the pace of credit flows but to dampen mounting demands on banks for still further credit extensions" (1965 Annual Report, p. 64). 
The same pattern continued through August 1966. In February, the Committee's perception was that "business activity continued to advance vigorously - and the outlook was becoming increasingly expansive," and that "recent and prospective economic developments clearly called for added policy measures to dampen the rise in aggregate demands" (1966 Annual

Report, pp. 127, 129). In August, "the economic outlook remained expansive, and prospects were for continuing high levels of resource use and strong upward pressures on wages and prices." Military, investment, and consumption spending were all viewed as contributing to the expansion (1966 Annual Report, p. 171 ).

Thus the Federal Reserve's shift to tighter monetary policy in $1965-66$ does not belong on a list of episodes in which the Federal Reserve was actively attempting to induce a downturn. By our criteria, it would be no more appropriate to include this episode than to include, for example, the shift to tighter policy in 1950 to counteract the expansion that the Federal Reserve expected because of the outbreak of the Korean war. ${ }^{11}$

December 1968. From mid-1967 to late 1968, the Federal Reserve gradually tried to adopt tighter policies as it became clear that the "minirecession" of 1966-67 would not turn into a full-fledged downturn and as growth became stronger. As before, such a shift in the specifics of monetary policy in response to economic developments does not represent a monetary shock. But at roughly the end of 1968 there appears to have been a change in the goals of policy: the Federal Reserve began to feel that it should act to reduce inflation. There were frequent references to "the prevailing inflationary psychology," to the fact that "inflationary expectations remained widespread," to "expectations of continuing inflation," and so on. ${ }^{12}$ Concern about inflation caused the Federal Reserve to attempt to maintain tight monetary policy despite evidence of considerably weaker real growth. In March 1969, for example, despite reductions in present and projected growth, "the committee agreed that, in light of the persistence of inflationary pressures and expectations, the existing degree of monetary restraint should be continued at present" (1969 Annual Report, p. 121). In May, "The Committee took note of the signs of some slowing in the economic expansion and of the indications of stringency in financial markets. In view of the persistence of strong inflationary pressures and expectations, however, the members agreed that a relaxation of the existing degree of monetary restraint would not be appropriate at this 
time" (1969 Annual Report, p. 145). In October, faced with projections of essentially no real growth over the coming three quarters, "the Committee decided that a relaxation of monetary restraint would not be appropriate at this time in light of the persistence of inflationary pressures and expectations" (1969 Annual Report, pp. 185-86). The considerations guiding monetary policy were similar at most other meetings during the year, and inflation and inflationary expectations received great attention and concern throughout. The intent to do more than offset expected increases in aggregate demand is clear. ${ }^{13}$

April 1974. The Federal Reserve responded to the oil embargo that started in October 1973 with an attempt to loosen policy somewhat to mitigate the contractionary influences and uncertainty generated by the embargo. With the lifting of the embargo in March 1974 and the end of wage and price controls in April, the federal Reserve was faced with a rate of inflation even higher than one that it had already considered excessive in the fall of 1973. It responded with an active effort at contraction. Throughout the spring and early summer, whenever there was conflict between the system's short-run interest rate and money targets, the FOMC, in contrast to its practice in earlier years, resolved the doubts in whichever way produced the higher interest rate. Indeed, on several occasions the Committee pursued (or accepted) higher interest rates despite the fact that monetary growth was within its target range. ${ }^{14}$ This occurred in an environment where little or no real growth was taking place or was expected in the near future. The motive for the attempts at contraction was inflation. There were references to "the persistence of inflation and of inflationary psychology" and "the need for policy actions to counter inflationary expectations." In one typical discussion, the central considerations were described as "the rise in market interest rates, the strong performance of the monetary aggregates, and -- more broadly -- the rapid advances in prices and costs."1s

1975-78. At the end of the 1973-75 recession in early 1975, the Federal Reserve faced a rate of inflation that was high by historical standards. Over the next few years, inflation was a constant concern of the System. The level of inflation was often cited as a reason for tight policy, and policy was frequently described as "anti-inflationary" or as based on an underlying objective of a gradual return to stable prices. Thus 
one can argue that the Federal Reserve was attempting to shift the aggregate demand curve back throughout this period.

In our judgment, however, this interpretation of Federal Reserve objectives would be incorrect. Given the level of inflation, expressions of concern about inflation, and of desires to reduce inflation, were inevitable. But the actual commitment to combat inflation appears to have been weak. It was not until April 1976 that "it was observed that this might be an opportune time for the Committee to take a small step toward its longer-range objective of returning growth in the monetary aggregates toward rates consistent with general price stability" (1976 Annual Report, p. 203 ). Target annual monetary growth rates, which were not the central focus of policy, were lowered only one to two percentage points over the next two years, and little other explicit anti-inflationary action was taken. More importantly, the few comments that relate to the output or employment goals of policy reveal that the Federal Reserve was not attempting to cause discernible output sacrifices to reduce inflation. In February 1978, one FOMC member expressed the view that "a realistic objective for the unemployment rate now was considerably higher than it used to be, perhaps as high as $51 / 2$ to 6 per cent" (1978 Annual Report, p. 132). This suggests that previously policy had been aiming at an even lower rate. In May of that year, when the unemployment rate was 68, "a few members observed that ... it would be desirable for growth in real output to diminish in the second half of this year toward a rate that could be sustained for the longer term," again implying that the Federal Reserve had previously been aiming for growth above trend rates (1978 Annual Report, p. 176).

August 1978. After several years of expressing concern about inflation but taking little concrete action to combat it, Federal Reserve policy changed significantly in 1978. In August, the FOMC recognized the "possibility that an appreciable slowing of inflation would prove more difficult to achieve than previously had been anticipated" (1978 Annual Report, p. 210). Steps to tighten policy began in August, and in November the government announced a major program to strengthen the weak dollar and combat inflation. The discount rate was raised from $71 / 4$ to $91 / 2 \%$ in four steps from August to November 1978, and reserve requirements were also increased in November. By November the System was fairly explicit that its objective was to cause a growth recession. The tightening of policy was continued despite forecasts of sluggish growth, and despite the fact that 
"skepticism was expressed [by some members of the FOMC]. . . that growth in output could be tapered down to a relatively slow rate without bringing on a recession" (1978 Annual Report, p. 247).

The tightening of policy continued in 1979. The discount rate was raised another $11 / 2$ percentage points in three steps from July to September. During this period almost all questions about the conduct of monetary policy were resolved on the side of tightness. When money growth was high the system acted to raise interest rates and damp growth; when money growth was low no actions were taken to lower interest rates and spur growth. All of this occurred against a background of a deteriorating forecast for short-run real growth (including a belief in the summer of 1979 that a recession was underway), which would typically have led to efforts to stimulate the economy. This clearly indicates a desire to contract the economy rather than just hold it steady.

October 1979. There was another major anti-inflationary shock to monetary policy on October 6, 1979. In effect, the Federal Reserve decided that its measures over the previous year had been unsuccessful in reducing inflation and that much stronger measures were needed. Although the shift in policy was to some extent presented as a technical change, the fact that it was intended to lead to considerably higher interest rates and lower money growth was clear. For example, "the committee anticipated that the shift ... would result in ... a prompt increase ... in the federal funds rate" (1979 Annual Report, p. 204). The upper end of the short-run target range for the federal funds rate was raised by $33 / 4$ percentage points, while the lower end was essentially unchanged. It was also clear that a central underlying objective of the change in policy was a reduction in inflation. For example: "the purpose of this series of actions [taken on october 6] was to assure better control over the expansion of money and bank credit and to help curb speculative excesses in financial, foreign exchange, and commodity markets, thereby dampening inflationary forces in the economy" (1979 Annual Report, p. 109).

Intents versus Actions. Our definition of a shock and our discussion of particular episodes makes it clear that our central concern has been with the intentions rather than the actions of the Federal Reserve. We do this because the same actions can occur both independently of the real economy and in response to real events. For example, the monetary base could fall because the Federal Reserve wished to cause a recession or because it was 
attempting to damp an expansion that it believed would otherwise have occurred. Thus, only a narrative analysis of intentions can identify changes in policy that are independent of the real economy.

At the same time, however, intentions not backed up by actions would not be expected to have large real effects. It is for this reason that we only consider as shocks episodes when the Federal Reserve genuinely appeared willing to accept output losses. We feel that it is only in these instances that the Federal Reserve is likely to actually use the tools it has available to contract the economy. In this regard, it is useful to note that while actions were not explicitly considered in our identification of shocks, financial market conditions did change greatly in each of the episodes in which we identify a shock. In particular, interest rates rose sharply. For example, from three months before our shocks to three months after, the six-month commercial paper rate rose by an average of 298 . The smallest increase was 168 (for the 1968 shock) and the largest 40 ) (for the 1955 shock). Thus, the Federal Reserve's intentions appear to have been supported by actions. ${ }^{16}$

\subsection{Does Real Activity Respond to Monetary Shocks?}

Having identified this sequence of six postwar episodes in which the Federal Reserve appears to have deliberately tried to cause a recession to reduce inflation, the natural question to ask is whether recessions in fact followed these disturbances. In this section, we provide both informal evidence and a statistical test of the relationship between our monetary shocks and the subsequent behavior of industrial production and unemployment in the post-World War II period.

Informal Evidence. We first examine the behavior of output and unemployment after each of the postwar shocks that we have identified. The data used in this analysis are the monthly total industrial production series compiled by the Federal Reserve Board and the monthly unemployment rate of all civilian workers compiled by the Bureau of Labor Statistics." In both cases we use the seasonally unadjusted version of the series and then account for seasonal movements by regressing the series on a set of seasonal dumny variables.

Figure 1 shows the resulting seasonally adjusted industrial production (in logarithms) and unemployment rate series. We have drawn vertical lines in the six months in the postwar era in which we identify monetary shocks. 
From these graphs it appears that real economic activity decreases substantially after each of our monetary shocks. The results are particularly striking for the unemployment series: the unemployment rate rises sharply after each shock. Industrial production also falls substantially after each shock, although these movements are somewhat obscured by the high monthly variation in the series and the strong upward trend. Another striking characteristic of Figure 1 is that there are only two major decreases in real activity that are not preceded by monetary shocks. Again, this feature is most apparent in the unemployment series. The two significant rises in unemployment that are not preceded by a monetary shock occur in 1954 (at the end of the Korean war) and in 1961. While these graphs are suggestive, simple plots of the data cannot distinguish between movements in real activity caused by monetary shocks and movements that occur because the economy may naturally tend to cycle up and down. To abstract from the typical cyclical behavior of real activity, we do the following. We first estimate univariate forecasting equations for both industrial production and unemployment, and then examine the difference between the forecasted behavior and the actual behavior of each series following each shock. If actual activity is less than one would expect on the basis of the univariate forecast following monetary shocks, this would suggest that the change in Federal Reserve policy caused real activity to be lower than it otherwise would have been.

The data used in the regressions are the same two seasonally-

unadjusted series described above. For industrial production we examine the data in percentage changes to account for the nonstationarity of the series. For the unemployment rate, we look at the data in levels and include a simple linear time trend to account for the apparent upward drift of the series over time. For each series, the simple forecasting equation includes a set of monthly dumy variables to account for typical seasonal

fluctuations and 24 own lags.

The own lags are included to capture the normal dynamics of the series. Most importantly, we wish to control for the possibility that Federal Reserve policy tends to turn contractionary after periods of strong growth that might naturally be followed by downturns even in the absence of a shift in monetary policy. The estimation of the unemployment equation in levels with a trend term included is done as an additional precaution in this regard. Because including a trend term can introduce bias toward detecting trend reversion when none is present, by using this procedure we 
may in fact be introducing some bias against finding real effects of monetary policy.

The results of estimating the equations suggest that our specifications are adequate to capture the typical behavior of the two series. The Q-statistics of the estimated regressions show that no significant serial correlation remains when 24 own lags are included. Furthermore, expanding the regressions to include as many as 48 own lags does not alter any important features of the results.

The forecasting equations are estimated over the period 1948-87. We then do a dynamic forecast of both the percentage change in industrial production and the level of the unemployment rate for the 36 months following each of the six shocks identified above. The differences between these forecasts and actual behavior are shown in Figures 2 and 3 . For industrial production, the figure shows the cumulative error at each point so that one can more readily identify the impact of the shock on the level of industrial production.

Consider first industrial production. Figure 2 shows that after each of the six times in the postwar period that the Federal Reserve shifted to a policy of attempting to contract output to reduce inflation, industrial production over the next several years was considerably lower than would be predicted on the basis of the past history of the series. The average maximum departure of industrial production from its forecasted path over the three year horizon considered in the figure is

-14\%. The smallest maximum forecast error is $-8 \%$ (for the August 1978 shock); the largest is $-21 \%$ (for the October 1979 shock).

Figure 3 shows that the results using unemployment are, with one exception, similar to those using industrial production. The unemployment rate two years after a monetary shock is typically 1.5 to 2.5 percentage points higher than the value predicted from the univariate forecasting regression. The exception is the behavior of unemployment following the policy shift of December 1968. In this episode, though industrial production fell sharply below its predicted path, the unemployment rate rose only slightly more than the univariate forecasting model predicts. Figure 1 shows that unemployment rose sharply after December 1968, but from an extremely low level. Thus, our forecasting equation is implying that the rise in unemployment was largely predictable simply on the basis of normal reversion toward trend. Since, as mentioned above, the inclusion of a trend term in the forecasting equation can cause the amount of trend reversion to 
be overestimated, Figure 3 may understate the size of the unforecastable increase in unemployment in this episode.

In short, the figures show that the negative monetary shocks that we have identified are followed by marked downturns in real economic activity that cannot be predicted from the past behavior of the economy.

Furthermore, the consistency of the results suggests that no one shock will be crucial to any statistical summary of the relationship between monetary disturbances and real output. This finding is important because although one could imagine that in specific episodes some omitted variable (supply shocks in 1974, for example) might be the source of both the real decline and the Federal Reserve's policy shift, it seems unlikely that some omitted factor is present in all six of the episodes.

Another important feature of the results is that the forecast errors typically do not return to zero. For every shock except that in 1947 , industrial production is substantially below its forecasted path three years after the shock. On average over the six shocks, industrial production after three years is 78 below the predicted level; that is, only about half of the maximum departure from the forecasted path has been reversed. Carrying the forecasts out further shows only a very gradual return to the predicted path: the average forecast error is 68 after four years and 48 after five. The same pattern is present, though somewhat less strongly, for unemployment; after four of the six shocks, the forecast errors for unemployment remain substantially above zero after three years.

An extreme interpretation of this finding would be that monetary shocks have real effects that are not only substantial but permanent. However, as Cochrane (1988) shows, simple autoregressive procedures such as ours cannot reliably distinguish between permanent effects and very longlasting but nonetheless transitory ones. Hence, a more moderate interpretation is that our results imply that monetary shocks have very long-lived effects. In either case, since we find that purely nominal disturbances have highly persistent effects, our results cast grave doubt on arguments that the considerable persistence of output movements suggests that demand disturbances cannot be an important source of output fluctuations (Nelson and Plosser, 1982; Campbell and Mankiw, 1987). Similarly, our results suggest that using the assumption that demand shocks have only temporary effects as an identifying assumption is likely to yield highly misleading results (Blanchard and Quah, 1988). 
Statistical Test. To test formally whether there is an identifiable statistical relationship between the monetary shocks that we have identified and movements in real output, we employ the following test. To the simple univariate forecasting equations for industrial production and unemployment described above, we add current and lagged values of a dummy variable that is equal to one in each of the six months in which we have identified a change in Federal Reserve policy and zero in all other months. The impulse response function for this expanded forecasting equation provides an estimate of the total effect of a policy change after some horizon. The standard error of the impulse response function provides a way of gauging whether the effects of the nominal disturbances are statistically significant.

Since the dummy variable is the crucial indicator of monetary shocks, it is useful to describe its specification more thoroughly. This variable simply identifies the six months when the Federal Reserve made a decision to try to cause a recession to reduce inflation. The variable does not indicate how long the shocks lasted or attempt to differentiate the shocks by size. The decision not to specify duration was motivated largely by the fact that the ends of these contractionary policies are often much more gradual and difficult to identify than the adoptions of the policies. The decision to give each shock an equal weight was motivated by the fact that our reading of the FOMC minutes and the Record of Policy Actions did not provide evidence of large differences in the severities of the intended downturns or a way of calibrating those intentions.

As before, the equation is estimated for both the percentage change in industrial production and the level of the unemployment rate. The actual equation that is estimated is:

$$
y_{t}=a_{0}+\sum_{i=1}^{11} a_{i} M_{i t}+\sum_{j=1}^{24} b_{j} y_{t-j}+\sum_{k=0}^{36} c_{k} D_{t-k}
$$

where $y$ is either the change in log industrial production or the level of the unemployment rate, $M$ is a set of monthly dummy variables, and $D$ is the dummy variable for contractionary monetary shocks. For the unemployment equation a simple linear time trend is also included. The regressions are run over the period 1948-87. 
The estimation results for the industrial production equation are given in Table 1 . Over two-thirds of the coefficients on the monetary shock variable are negative and twelve of them have $t$-statistics less than -1.0 . The predominance of negative coefficients, like the pictures described above, suggests that negative monetary shocks do indeed depress real output. The fact that many of the coefficients have large standard errors indicates that the timing of the response of real output is somewhat variable. This, however, is not surprising given that we are trying to pinpoint the response at a monthly frequency. Indeed, what is perhaps more surprising is that the response in some of the months is estimated so precisely.

A natural way to summarize the response of industrial production to the monetary shock variable is to examine the impulse response function implied by the estimated equation. In our specification, the impulse response function traces out the effect of a unit shock to the dummy variable (D), including the feedback effect through lagged output. The 36month impulse response function for the industrial production equation is given in Figure 4." The figure also shows the one standard error bands for the impulse response function. ${ }^{19}$

The impulse response function shows that for the first several months following a monetary shock there is little effect on real output. Output then falls drastically at the ends of both the first and second years, with a slight plateau early in the second year. The maximum impact occurs after 33 months and indicates that a shock causes the level of real industrial production to be approximately 12 lower than it would have been had the shock not occurred.

From the confidence bands, it is clear that this effect is not only large, but also highly statistically significant. For example, the t-statistic for the impulse response function at 33 months is -3.4 . The effect of monetary shocks on real production is thus significantly different from zero at the 998 confidence level.

Another way to measure the statistical significance of our results is to ask how likely one would be to obtain estimated effects as strong as those shown in Figure 4 using random dates for shocks. Specifically, we performed 200 trials of an experiment in which we replaced the dummy variable in equation (1) with a dummy set equal to one in six months chosen randomly over the period 1947-85. The estimated maximum depressing effect of the Monte Carlo dumy on industrial production over a 36-month horizon exceeded the 128 figure obtained with our dumy for genuine monetary shocks 
in just one trial. Thus, it is extremely unlikely that our results could arise by chance.

Figure 4 also confirms the impression gained from Figure 2 that monetary shocks have real effects that are very long-lasting. By the end of 36 months only a quarter of the maximum negative effect of the monetary shock has been undone. Furthermore, if one includes an additional 24 lags of the monetary shock dummy in the basic regression and then continues the impulse response function out an additional 24 months, the negative effects of a monetary shock still linger. Five years after a monetary shock, industrial production is still 78 lower than it would have been had the Federal Reserve not decided to attempt to cause a recession.

The empirical results for unemployment confirm those for industrial production. Table 2 shows the coefficient estimates for the equation for the unemployment rate. The impulse response function and standard error bands for the unemployment regression are given in Figure 5 . The figure shows that unemployment begins to rise sharply 18 months after the shock and reaches its maximum at 34 months. The total impact of the shock after 34 months is that the unemployment rate is 2.1 percentage points higher than it otherwise would have been.

The standard error bands for the impulse response function for unemployment indicate that the depressing effect of a monetary shock is highly statistically significant. The t-statistics are over 2.0 for all the impulse responses after month 20 and are often over 3.0 . In a Monte Carlo experiment analogous to that for industrial production, the maximum estimated impact of the Monte Carlo dummy on unemployment over a 36-month horizon never exceeded 2.1 percentage points in 200 trials.

The results of the statistical test indicate that monetary policy shocks have potent real effects. There remains, however, the question of whether the monetary shocks we identify actually account for a large fraction of the total variation in real activity. Figure 1 provides informal evidence that monetary shocks are indeed an important source of real fluctuations. It shows not just that each of our shocks was followed by a sharp rise in unemployment, but also that there have been only two sharp rises in unemployment in the postwar period not preceded by such shocks. In other words, six of the eight postwar recessions have been preceded by decisions by the Federal Reserve to attempt to cause a downturn. To formalize the impression given by Figure 1, we first regress the monthly level of the unemployment rate on a constant, seasonal dummy 
variables, and a trend. We then run the same regression including 36 lags of our monetary shock dummy variable. That is, we run the same regression as in (1) above, except that we do not include any of the own lags of the unemployment rate. The equation including the monetary shock variable has a sum of squared residuals that is 218 smaller than that of the simple seasonal regression. This difference is very large. It implies that, by itself, our simple dummy variable for overt Federal Reserve policy decisions to create a recession can account for more than a fifth of the nonseasonal variation in the postwar unemployment rate.

These results strongly suggest that aggregate demand disturbances, rather than real shocks, are the predominant source of economic fluctuations. Our simple dumy variable surely captures only a small fraction of demand disturbances. It is a very crude measure of only one aspect of monetary policy, and it neglects all non-monetary demand disturbances, such as changes in fiscal policy and in private demand, entirely. Since the dummy variable alone accounts for a substantial fraction of (non-seasonal) postwar fluctuations, it follows that aggregate demand disturbances as a whole almost surely account for a much larger fraction.

Robustness. While the results appear clear-cut, one naturally worries about the robustness of any empirical finding. In the case of this study, the main concern is that the decisions by the Federal Reserve to try to create a recession might be correlated with other factors. If this is true, then these other factors, rather than the monetary shocks we have identified, could be the true source of the movements in real output.

We have already provided several pieces of evidence that indicate that this is not a likely possibility. First, the earlier part of this section discusses the rationale given by the system for its decisions to try to shift back the aggregate demand curve. While inflation was the proximate cause in each case, the perceived cause of the inflation differed across the episodes that we consider. For example, in 1968 it was wartime expenditures, while in 1974 it was earlier oil price shocks and expansionary monetary policy. The fact that there was no consistent source of the inflation that the Federal Reserve wished to cure suggests that there is no consistent alternative factor that was present in each instance of a shift to anti-inflationary monetary policy. 
Second, Figures 2 and 3 show that the behavior of real activity relative to predicted following each of our shocks is quite similar. This suggests that even if some other factor were causing inflation and depressing real output in one or two of the periods in which we have identified monetary shocks, this other factor could not be driving the results. We have tested this assertion by eliminating each shock in turn and examining the resulting impulse response functions. After each elimination, the impulse response functions appear nearly identical to those in Figures 4 and $5 .^{20}$

Third, our discussion of the simple forecasting equations stressed that 24 lags of the percentage change in industrial production or the level of the unemployment rate are adequate for capturing any natural tendency of real activity to decline after it has been growing briskly for some time. This means that if the Federal Reserve simply said it wished to cause a recession whenever a temporary boom was about to end, these statements would not have any explanatory power once the own lags were included in the regression. The results in Figures $2-5$ and Tables $1-2$ above clearly show that this is not the case."

In addition to these pieces of evidence, it is possible to control explicitly for other factors that one might fear accounted for our results. We consider three types of other factors. They are supply shocks, fiscal policy, and inflation itself.

Supply shocks are a natural source of concern: it is possible that supply shocks could both generate inflation to which the Federal Reserve wished to respond and directly depress real output. In this regard, it is important to point out that supply shocks that occurred in the past and were accommodated by expansionary aggregate demand policy are of no concern. These shocks would have caused the inflation that the Federal Reserve wished to cure but would no longer be having a depressing effect on real activity.

To ensure that supply shocks do not account for our results, we do two things. First, we try eliminating the two monetary shocks that could plausibly be associated with the oil price rises of the 1970 s $(1974$ and 1979). This change reduces the maximum impact of a shock slightly (the trough of the impulse response function for industrial production is -.10 rather than -.12 ), but the results are otherwise unchanged.

second, we add a measure of supply shocks to our regressions. Following conventional practice, we capture supply conditions by including the current and first 36 lags of the monthly percentage change in the 
relative price of food and energy in our regressions. ${ }^{22}$ We find that accounting for supply shocks barely alters the results. For industrial production the cumulative impact of a monetary shock is actually slightly larger when supply shocks are included in the regression than when they are not. For unemployment the maximum impact of a monetary shock is slightly smaller for the expanded regression than for the simple regression. In both cases the supply shock variable has little impact on the timing or the significance of the impulse response functions for the monetary shock variable. ${ }^{23}$

Another factor that one might worry could account for our results is fiscal policy. It could be the case that whenever the Federal Reserve became concerned about inflation and decided to attempt to cause a recession, the fiscal authorities also shifted to a more contractionary policy. This possibility does not appear particularly likely. In the Federal Reserve records there is certainly no mention that the antiinflationary changes in monetary policy are designed to reinforce shifts in fiscal policy. Furthermore, given the inside lags of fiscal policy, it seems unlikely that the fiscal authorities could change spending and taxes to match the timing of monetary policy very closely.

Nevertheless, it is perhaps useful to test whether a correlation between monetary and fiscal policies could be present and could affect the results. To do this, we add to our regressions the current and first 12 lags of the quarterly change in the ratio of the nominal government budget surplus to nominal GNP. "24 This variable should obviously capture any of the demand side effects of fiscal policy. At the same time, because the deficit is highly correlated with government purchases, this variable should also capture any supply side effects that government purchases might have through the interest rate and labor supply. Thus, it can control for another possible source of supply shocks.

Including the fiscal policy variable lowers the cumulative effect of the monetary shock variable only slightly. For both industrial production and unemployment, a monetary shock still causes a large downturn in economic activity that is statistically significant at at least the 998 confidence level. Thus, the apparent response of the real economy to monetary shocks cannot be ascribed to possible correlations of monetary disturbances with government spending. ${ }^{25}$

A final additional factor that we consider is inflation. It is difficult to think of a plausible channel through which inflation by itself 
(independently of supply shocks) might directly depress real output. Nevertheless, since inflation is obviously present during each of our episodes, it may be useful to check whether allowing for a direct effect of inflation on real activity alters our results. To do this, we include the current and first 36 lags of the monthly percentage change in the producer price index for finished goods in our basic regression. For industrial production, including inflation has virtually no effect on the shape, amplitude, or statistical significance of the impulse response function for a monetary shock. For unemployment, including inflation reduces the size of the total real effect of the monetary shock somewhat, but the cumulative impact after 33 months is still large and positive. In sum, in this case, as in the other cases discussed, the result that monetary shocks matter tremendously is robust to the inclusion of additional explanatory variables.

\section{FRIEDMAN AND SCHWARTZ REVISITED}

A natural next step in our analysis is to return to the interwar period to see what evidence the narrative approach sheds on the effects of monetary shocks in this era. We do this with some trepidation, however, because as we argue in section 2 , we believe that the identification of monetary disturbances in the period before 1947 can never be as clear-cut or convincing as it is in the postwar era. Nevertheless, since Section 2 suggests an alternative list of interwar shocks and section 3 suggests an empirical test for the relationship between monetary shocks and real output, it seems useful to investigate how, if at all, employing a revised version of the narrative approach affects Friedman and Schwartz's conclusion that monetary disturbances had severe real effects in the interwar era.

Specification. In section 2 we discuss in detail Friedman and Schwartz's identification of monetary shocks in the interwar period. We argue that there may be some bias in their choices, and thus that the list of shocks that they focus on may not be the most appropriate one. For our basic interwar test we therefore consider a list of shocks somewhat different from Friedman and Schwartz's. In particular, we identify monetary shocks in five months in the interwar period: January 1920, October 1931, February 1933, January 1937, and september 1941. This list differs from that considered by Friedman and schwartz by adding shocks in February 1933 and september 1941 and by not including any shock in the first two years of 
the Great Depression.

Our reasons for identifying shocks in 1933 and 1941 are described in

Section 2. We have two reasons for not including a shock in the early stages of the Great Depression. First, our concern throughout the paper has been with whether Federal Reserve policy actions have real effects. Since whatever monetary disturbance may have occurred in the early part of the Depression involved inaction rather than active changes in monetary policy, it seems reasonable to exclude it. Second, because the interpretation of monetary developments in the early stages of the Great Depression is so controversial, we do not want our results to be driven by the identification of a shock in this period. However, because the most appropriate selection of shocks for the interwar period is not clear-cut, below we consider alternatives to our basic list.

Given our list of shocks, it is straightforward to implement the statistical test of the real effects of monetary disturbances that we use in the previous section. As before, we define a monetary shock dummy variable that is equal to one in each of the months in which we identify a shock. The data on real output that we use are the standard Federal Reserve Board monthly index of total industrial production, which begins in $1919 .{ }^{26}$ The equation that we estimate is identical to that given in equation (1) above. The estimation period is 1921-44.

Results. The coefficient estimates of this regression are given in Table 3. Figure 6 shows the corresponding impulse response function, together with the one standard error bands. The point estimates suggest a very potent effect of monetary shocks on real economic activity. The estimated maximum effect of a monetary shock on industrial production is a fall of 208 after 18 months.

While the real effect of a monetary shock in the interwar era appears to be large, it is not estimated precisely. Over months 10 to 18 , when the effect is largest, the departure of the impulse response function from zero is 1.5 to 2 times the associated standard error. This implies that the hypothesis that the effect is zero is only marginally rejected at conventional significance levels. Thus, while the interwar results are entirely consistent with our finding for the postwar period that monetary disturbances have large real effects, they do not by themselves provide overwhelming evidence of those effects. 
At the same time, the timing of the real effects of monetary shocks in the basic interwar regression is quite different from the timing of real effects in the postwar regressions. In both eras the effect over the first six months is small. However, in the next twelve months the response is much more abrupt and severe in the interwar era than in the postwar era. The estimated impact of an interwar monetary shock plummets from essentially zero five months after the shock to -17 after eleven months. Industrial production then falls irregularly to its trough of $-20 \%$ after eighteen months. Then, again in sharp contrast to the results for the postwar period, there is a strong rebound, with the effect rising from $-20 \%$ to -3 \% by month 23 and disappearing entirely by month 29 .

In short, our results suggest that the effects of demand disturbances were both more rapid and less persistent in the interwar era than in the postwar period. An obvious implication of this finding is that -- in contrast to the position taken by De Long and Summers (1988) and others -an explanation of the change in the overall persistence properties of real output after world war II should be sought in changes in the mechanisms that determine the economy's response to a given type of shock, rather than in changes in the nature of the shocks themselves.

Robustness. As with our postwar regressions, it is important to investigate whether our results for the interwar era are being driven by the omission of other potentially relevant variables. Because our list of interwar monetary shocks includes one in the aftermath of world war I and another shortly before the outbreak of world war II, the most obvious omitted variable is some measure of fiscal policy.

We attempt to account for the effects of fiscal policy in two ways. Our first approach is to control directly for the effects of fiscal policy. We do this by including in the regression the current and two lagged values of the change since the previous year of the ratio of the federal budget surplus to nominal GNP. ${ }^{27}$ Adding this variable has little effect on the results. The coefficients on the fiscal policy variables are of the expected sign (that is, a decrease in the surplus increases output), but they are small and statistically insignificant. The impulse response function for a monetary shock in this expanded regression is virtually identical to that for the basic interwar regression.

The second method that we use to deal with the possible effects of fiscal policy is to exclude the two shocks associated with the world wars 
and shorten the sample period to February 1922 - December 1940. These changes greatly strengthen the estimated effect of monetary shocks. The maximum depressing effect of a monetary shock is now a fall in industrial production of 418 . The timing of the effects is essentially the same as for the basic interwar regression.

Finally, it is natural to contrast our results with those that would be obtained using Friedman and Schwartz's list of shocks. To do this, we define an alternative monetary shock dummy variable that is equal to one in the five months in the interwar era when Friedman and Schwartz identify a monetary shock: January 1920, October 1930, March 1931, October 1931, and January 1937. The five shocks include the "three crucial experiments," plus two shocks early in the Great Depression corresponding to the beginnings of the first two waves of banking failures." The specification is otherwise the same as our basic one. The sample period is February 1921 - December 1944 and no deficit measure is included.

The impulse response function for this regression is given in Figure 7 and shows, not surprisingly, that using Friedman and Schwartz's choices of shocks rather than ours greatly increases the estimated effects of monetary disturbances. The maximum effect of a monetary shock on real output is now a fall of 358 rather than 208 and is overwhelmingly, rather than marginally, significant. The pattern of the responses is similar to that obtained usinç our preferred list of shocks. The only noteworthy difference is that in Figure 7 output recovers only two-thirds of its maximum loss after 36 months rather than all.

Overall, the results from the interwar regressions support the postwar finding that monetary disturbances have very large effects on real economic activity. They are thus also supportive of Friedman and Schwartz's belief that money mattered tremendously in the interwar period. In fact, they may actually strengthen Friedman and Schwartz's conclusion because they indicate that the lagged effects of monetary shocks are shorter and sharper than informal statistical procedures led Friedman and Schwartz to believe."

\section{CONCLUSION}

This paper is based on two premises. The first is that the narrative approach is the method that is most likely to be persuasive in resolving the question of whether monetary disturbances have real effects. The use of the 
narrative approach allows a vast body of information that cannot be employed in conventional statistical tests to be brought to bear on this question. And it is this additional information that can solve the problem of identifying the direction of causation between monetary factors and real economic developments. The second premise is that employing the narrative approach is difficult. Using it casually, as is typically done, can lead to bias, either in the interpretation of the historical record or in the inference that one draws about the real effects of monetary shocks.

This paper is therefore an attempt to employ the narrative approach carefuliy and systematically to study the real effects of monetary disturbances. The first and last parts of the paper focus on the interwar era, and are thus largely a reexamination of Friedman and Schwartz's pathbreaking work. The middle and more important part considers evidence for the period after world war II. From these two types of analysis we reach five conclusions.

First, in the postwar era there have been a series of episodes in which the Federal Reserve has in effect deliberately attempted to induce a recession to decrease inflation. These episodes are virtually ideal for employing the narrative approach because monetary shocks can be identified using a narrow and concrete set of criteria that are consistent across episodes. Economic developments following these shifts in Federal Reserve policy provide decisive evidence of the importance of monetary policy. In every case, output fell substantially below what one would otherwise have expected. A shift to anti-inflationary monetary policy led, on average, to an ultimate reduction in industrial production of 128 and an ultimate rise in the unemployment rate of two percentage points. These effects are highly statistically significant.

Second, in the postwar era the maximum depressing effect of antiinflationary shifts in monetary policy occurs after roughly two and one half years, and there appears to be only a limited tendency for real activity to then return toward its pre-shock path. In other words, the real effects of demand disturbances appear to be highly persistent.

Third, our extremely narrowly defined monetary disturbances account for a considerable fraction of fluctuations in postwar economic activity: our dummy variable for negative shifts in policy accounts for more than a fifth of the variation in detrended, deseasonalized unemployment in the postwar period. Because we find that demand disturbances have real effects 
and because our simple measure of monetary shocks almost surely captures only a small fraction of demand fluctuations, our results strongly suggest that demand disturbances are a primary source of postwar economic fluctuations.

Fourth, the narrative approach is extremely difficult to implement in the interwar period. There is so much variation in monetary institutions and doctrines and in economic events that it is almost impossible to study the historical record of the period systematically. When the set of monetary disturbances for the interwar period that, in our judgment, comes as close as possible to being free of bias is considered, the interwar evidence is also supportive of the view that monetary policy has large real effects. The estimated maximum effect of a monetary disturbance for this period is a reduction in industrial production of $20 \%$.

Fifth and last, the real effects of monetary shocks in the period between World war I and World war II do not appear to be long-lasting. Our estimates imply that by 33 months after a shock, output has essentially returned to the path it would have followed in the absence of the shock. Thus our results imply that demand disturbances have large real effects in both the interwar and postwar eras, but that the persistence properties of those real effects are very different in the two periods. 


\section{REFERENCES}

Bernanke, Ben S. 1983. "Nonmonetary Effects of the Financial Crisis in the Propagation of the Great Depression." American Economic Review 73: $257-76$.

Blanchard, Olivier Jean and Danny Quah. 1988. "The Dynamic Effects of Aggregate Demand and Supply Disturbances." NBER Working Paper No. 2737 .

Bordo, Michael D. 1988. "The Contribution of A Monetary History of The United States: 1867 to 1960 to Monetary History." NBER Working Paper No. 2549 .

Brown, E. Cary. 1956. "Fiscal Policy in the 'Thirties: A Reappraisal." American Economic Review 46: 857-79.

Campbell, John Y. and N. Gregory Mankiw. 1987. "Are Output Fluctuations Transitory?" Quarterly Journal of Economics 102: 857-80.

Chandler, Lester V. 1970. America's Greatest Depression, 1929-1941. New York: Harper and Row.

Cochrane, John H. 1988. "How Big Is the Random walk in GNP?" Journal of Political Economy 96: 893-920.

De Long, J. Bradford and Lawrence H. Summers. 1988. "How Does Macroeconomic Policy Affect Output?" Brookings Papers on Economic Activity, 433-80.

Friedman, Milton and Anna Jacobson Schwartz. 1963a. A Monetary History of the United States, 1867-1960. Princeton: Princeton University Press.

$$
\text { and 1963b. "Money and Business Cycles." Review of }
$$
Economics and Statistics 45: $32-64$.

Gordon, Robert Aaron. 1974. Economic Instability and Growth: The American Record. New York: Harper Row.

Gordon, Robert J. and James A. Wilcox. 1981. "Monetarist Interpretations of the Great Depression: An Evaluation and Critique." In The Great Depression Revisited, ed. Karl Brunner, 49-107. Hingham, Mass.: Martinus Nijhoff Publishing.

Hamilton, James D. 1987. "Monetary Factors in the Great Depression." Journal of Monetary Economics 19: 145-69.

Hendry, David F, and Neil R. Ericsson. 1987. "Assertion without Empirical Basis: An Econometric Appraisal of Monetary Trends ... in the United Kingdom by Milton Friedman and Anna J. Schwartz." Oxford University Applied Economics Discussion Paper No. 25.

Kareken, John and Robert M. Solow. 1963. "Lags in Monetary Policy." In Commission on Money and Credit, Stabilization Policies, 14-96. 
Kendrick, John w. 1961. Productivity Trends in the United States. Princeton: Princeton University Press.

Kindleberger, Charles P. 1986. The World in Depression, 1929-1939. Revised edition. Berkeley: University of California Press.

King, Robert G. and Charles I. Plosser. 1984. "Money, Credit, and Prices in a Real Business Cycle." American Economic Review 74: 363-80.

Maddison, Angus. 1982. Phases of Capitalist Development. Oxford: Oxford University Press.

Nelson, Charles R., and Charles I. Plosser. 1982. "Trends and Random Walks in Macroeconomic Time Series." Journal of Monetary Economics 10: 13962 .

Poterba, James M., Julio J. Rotemberg, and Lawrence H. Summers. 1986. "A Tax-Based Test for Nominal Rigidities." American Economic Review 76 : 659-75.

Romer, Christina D. 1988a. "World War I and the Postwar Depression: A Reinterpretation Based on Alternative Estimates of GNP." Journal of Monetary Economics 22: 91-115.

1988b. "The Great Crash and the Onset of the Great Depression." NBER Working Paper No. 2639.

Schwartz, Anna J. 1981. "Understanding 1929-1933." In The Great Depression Revisited, ed. Karl Brunner, 5-48. Hingham, Mass.: Martinus Nijhoff Publishing.

Summers, Lawrence. 1987. "What is Memorable in Empirical Macroeconomics?" Harvard University, unpublished manuscript.

Temin, Peter. 1976. Did Monetary Forces Cause the Great Depression? New York: W. W. Norton \& Company.

manuscript.

1988. "The Cause of the Great Depression." MIT, unpublished

Tobin, James. 1965. "The Monetary Interpretation of History: A Review Article." American Economic Review 55: 464-85.

United States Board of Governors of the Federal Reserve System. Annual Report. Various years.

- Federal Reserve Bulletin. Various years.

- Industrial Production. 1986 Edition.

- Minutes of Federal Open Market Committee. Various years.

United States Bureau of Economic Analysis. 1986. National Income and Product Accounts, 1929-1982, U.S. Government Printing Office. 
United States Bureau of Labor Statistics. 1988. Labor Force

Statistics Derived from the Current Population Survey, 1948-87.

U.S. Government Printing office.

- Monthly Labor Review. Various issues.

United States Bureau of the Census. 1949. Historical Statistics of the United States, 1789-1945. Washington, D.C.: U.S. Government Printing office.

United States Department of the Treasury. 1980. Annual Report of the Secretary of the Treasury, 1978-79. U.S. Government Printing Office. 
1. Summers (1987) provides a cogent discussion of the persuasiveness of narrative studies.

2. Many other authors have explored various aspects of Friedman and Schwartz's work. To cite only a few of the most prominent examples, Temin (1976), Gordon and Wilcox (1981), and Hamilton (1987) study Friedman and Schwartz's analysis of the Great Depression, and Bordo (1988) assesses their contributions to monetary history more generally. Hendry and Ericsson (1987) criticize Friedman and Schwartz's econometric methods, focusing mainly on their later work.

3. We also exclude the episodes that Friedman and Schwartz cite as providing evidence of the effects of monetary disturbances on nominal income, notably the secular deflation of 1879-1897 and the secular inflation of 1897-1914. In the early 1960s, when Friedman and schwartz wrote, there was widespread agreement that shifts in aggregate demand had important real effects but not that changes in money had important effects on aggregate demand. Thus to Friedman and Schwartz, evidence that monetary disturbances affected either output or prices was evidence that "money mattered." Today, of course, the central motive for interest in the effects of monetary disturbances is the desire to gain insight into the question of whether aggregate demand shocks have real effects.

4. It can be argued that this negative shock was followed by a positive shock from Roosevelt's gold policies. While changes in competitiveness arising from the rise in the dollar price of gold in 1933 could certainly have stimulated the economy through increased net exports, Chandler stresses that Roosevelt's gold policies "did not begin to make additions to the monetary base or bank reserves until after the adoption of the Gold Reserve Act at the end of January 1934" (1970, p. 164). Thus, any monetary component to this positive shock did not occur until nearly a year after the negative monetary shock of early 1933. Furthermore, if one follows the logic of Friedman and Schwartz, there may be no monetary shock at all in 1934 because an expansion of high powered money is the usual and expected reaction to severe depression.

5. A final episode that is not identified in the Monetary History as a major shock, but that could be considered a change in monetary policy, is the contractionary open market operations and increases in the discount rate that began in January 1928 (see, for example, Hamilton, 1987; Schwartz, 1981: and Temin, 1988). While we agree that money became tighter in this period, it is not clear whether this tightening should be viewed as unusual or simply as a usual reaction to real economic events such as the boom in real output and stock prices. Furthermore, we also agree with Friedman and Schwartz that the tightening in 1928 was fairly small, especially when considered relative to the contractionary shocks in 1920, 1931, and 1937. As they note, the Federal Reserve "followed a policy which was too easy to break the speculative boom, yet too tight to promote healthy economic growth" (1963, p. 291). (Gordon and Wilcox, 1981, and Hamilton, 1987, also provide evidence that the monetary shock in 1928-1929 was small relative to the subsequent decline in real output.) Hence, unless one uses a procedure that calibrates shocks according to severity, it is prudent to not identify the 1928 tightening as a monetary shock. 
6. Throughout the paper, percentage changes refer to differences in logarithms.

7. For 1918-21, the GNP data are from Romer (1988a, Table 5) and the government purchases data are from Kendrick (1961, Table A-IIa). The data for 1944-47 are from the National Income and Product Accounts.

8. As an accounting matter, the swing from rapid growth of the money stock from 1934 to 1937 to a decline in 1937-38 was primarily the result of a sharp decline in the growth rate of high-powered money. This in turn appears to have stemned largely from a switch by the Treasury to sterilizing gold inflows in the first three quarters of 1937 . Friedman and schwartz do not discuss the reasons for this change in Treasury policy. (1963a, pp. 509-511.)

9. See for example the FOMC meetings of Jan 11, June 22, and July 12, 1955 (1955 Annual Report, pp. 90, 98, 100).

10. See for example the Record of Policy Actions for the FOMC meetings of Jan. 10, Feb. 15, March 6, and April 17, 1956.

11. On the basis of the Record of Policy Actions one could argue for a similar interpretation of the shift to tighter policy in october of 1947. The record for the FOMC meeting of October 6-7 states: "In the period since the previous meeting of the Committee conditions affecting the money market had changed considerably. Inflationary pressures had increased and there were indications that they would continue to be strong in the months immediately ahead" (1947 Annual Report, p. 95). The interpretation that the Federal Reserve was attempting to do more than offset shocks to aggregate demand appears more compelling, however, for two reasons. First, it is very plausible that the minutes could be much franker than the Record of Policy Actions concerning any desire to cause a recession. Second, inspection of the reasons that the Federal Reserve gave in support of the view that inflationary pressures were increasing strongly suggests that what they meant was simply that in the absence of tighter policy, inflation and high output would continue. For example:

"Inflationary pressures have been strong in our economy during the past few months, and there is ample indication that these pressures will continue strong, and perhaps be accentuated, in the months immediately ahead. The basic causes of this situation are well known. A vast supply of money and other liquid assets was created during the war and there have been additions to this accumulation of purchasing power since the end of the war. There has also been an inadequate supply of goods and services ... growing out of the destruction of war and the deferment of civilian demands when a large part of output was destined for military use.... The existing situation, therefore, spells continuing pressure toward higher prices. In addition we must take cognizance of the fact that conditions are highly favorable to further credit expansion ...." (From a letter from the FOMC to the Secretary of the Treasury; Minutes 1947, pp. 183-4).

Aside from the phrase "and perhaps be accentuated," what was being argued was simply that, in the absence of tighter policy, prices, credit, and money would continue to increase. 
12. The quotations are from the Records of Policy Actions of the FOMC meetings of Dec. 17, 1968, Jan. 14, 1969, and March 4, $1969--1968$ Annual Report, p. 224, and 1969 Annual Report, Pp. 109, 117.

13. One can plausibly argue that the shock could be dated a month or two later than December 1968. The tightening that occurred in December was in part a response to evidence of stronger growth. By early 1969, however. it was clear that the change in policy involved more. We choose December 1968 because the Federal Reserve cites this as the time when "the Federal Reserve System embarked on a policy of increased monetary restraint" (1969 Annual Report, p. 75). Dating the shock in March 1969 has no important effects on our results.

14. See especially 1974 Annual Report, pp. 165, 173, 180-1.

15. 1974 Annual Report, pp. 109, 108, and 108, respectively. The statements occur in explanations of decisions by the Board of Governors to deny proposed increases in the discount rate. Nonetheless, they are meant to describe the basic stance of policy.

16. Using the federal funds rate for the five episodes that have occurred since the development of the federal funds market does not alter these results. The growth rate of the monetary base also generally slows around the times of the shocks, though its movements across episodes are less consistent than those of the commercial paper rate. The reason for this greater variability is very likely simply that in all of the episodes (including the 1979 one) the Federal Reserve focused to. a considerable extent on interest rate movements, while in many of the episodes it was relatively unconcerned with the monetary base.

17. The industrial production series is from Industrial production, 1986 Edition, Table A-1l. The unemployment series is from Labor Force Statistics Derived from the Current Population Survey, 1948-87, Table A-31. The unemployment series for 1946 and 1947 is taken from various issues of the Monthly Labor Review. The data for 1946 and 1947 are based on the same household survey as later estimates, but have not been revised to take into account modern changes in the definition of the labor force. To prevent a spurious jump in the series in January 1948, we splice the old and new series together in this month.

18. As in Figure 2, Figure 4 shows the cumulative sum of the impulse responses so that the effect of the shock on the log level of industrial production can be seen more easily.

19. The standard errors are calculated using the formula for the asymptotic standard error of a non-linear function of the regression parameters. See Poterba, Rotemberg, and Summers (1986, p. 668) for details.

20. Even though it does not represent a monetary shock by our criteria, the "credit crunch" of 1965-66 is often characterized as an important episode of tight monetary policy. We have therefore investigated the effects of adding a shock in December 1965 . We find the results are essentially unchanged by this addition. 
21. A related point concerns our method for identifying shocks. To identify a change in monetary policy we often use Federal Reserve records for up to six months after the apparent change. We do this because shifts in policy are often not sufficiently sudden or dramatic that they can be identified from, for example, the records of a single meeting. This introduces a slight possibility of bias: if the system has a tendency to state that it was attempting to create a downturn only if evidence that there will be a downturn has appeared, our test will overstate the effects of shifts in policy. To ensure that this possible bias is not affecting our results, we look at the forecast errors of the simple univariate forecasts starting six months after each shock. Even with these six extra months of actual data, however, the declines in output that occur following the monetary shocks cannot be predicted.

22. The relative price of food and energy is measured as the ratio of a weighted average of the producer price indexes for crude foodstuffs and feedstuffs, crude fuel, and crude petroleum to the producer price index for finished products.

23. The same results obtain when alternative measures of supply shocks are used. Among the variants we have tried are the percentage change in the relative price of crude petroleum and the percentage change in the relative price of all crude materials for further processing.

24. The budget surplus data are from the National Income and Product Accounts and cover both the federal government and state and local governments. Quarterly observations were included by assuming that the deficit to GNP ratio was constant over a quarter, and then measuring the change in the ratio between the current month and 3 months ago, between 3 and six months ago, and so on.

25. Using the ratio of the cyclically-adjusted federal budget surplus to nominal GNP rather than the fiscal policy measure employed in the text has essentially no effect on the results. Specifically, we employ the Bureau of Economic Analysis measure of the cyclically-adjusted surplus (from CITIBASE), which is available beginning in 1955. Adding the current and first twelve lags of the quarterly change in the ratio of this measure to nominal GNP to our basic regression estimated over the period 1958-1987 has virtually no impact on the estimated impact of the monetary shock dummy.

26. We use the most recent version of this series (given in Industrial Production, 1986) and again use seasonally unadjusted data. While the FRB index is the best and most comprehensive monthly index of production available for the interwar period, it is not without problems. Most importantly, there is a break in the series in 1923. For the period after 1923, the FRB revised its original index to have broader coverage by including data on manhours for those industries where direct measures of physical production were unavailable. This revision was not carried back to the period 1919-1923 because the necessary data were unavailable. This difference in procedures is potentially important because the inclusion of the manhours data tends to reduce the volatility of the FRB index after 1923. This means that some of the relatively dramatic movements in the index for 1919-1923 would probably disappear if the earlier series were constructed using the same methods as the later index. Because we want to include the 1920 monetary shock, starting the estimation in 1923 and thus using only the unbroken series is not possible. 
However, to test whether the inconsistency in the data affects our empirical results, we do the following. Since the revision of the Fed series to include manhour data was not done until 1940, there exists a consistently bad FRB index for 1919 to 1940. We can use this consistent series in the regressions and see if it yields results that are noticeably different from those based on the inconsistent series. We find that the results are very similar for both the consistent and inconsistent data. We therefore opt for the inconsistent data because they exist after 1940 and thus allow us to examine the real effects of the rise in reserve requirements in late 1941.

27. The budget variable used is the nominal administrative budget surplus or deficit given in the statistical appendix of the Annual Report of the Secretary of the Treasury, 1980, Table 2. The nominal GNP numbers are from Romer, 1988a, Table 5, and the National Income and Product Accounts of the U.S, Table 1. Both the budget and the GNP data are only available annualiy. Monthly figures are set equal to the annual value and changes are calculated in multiples of 12 .

28. It is difficult to date precisely the monetary shock (or shocks) that Friedman and Schwartz associate with the early stages of the Great Depression. We choose October 1930 and March 1931 because it is in reference to the banking crises that Friedman and Schwartz are most emphatic in arguing that monetary policy was highly unusual. Including only the "three crucial experiments" rather than all five shocks has little effect on the results.

29. An obvious implication of the conclusion that monetary policy had large real effects in the interwar period is that the Great Depression would have been less severe if monetary policy had been less contractionary. In that sense, our results are supportive of Friedman and Schwartz's interpretation of the Depression. But since, as described above, neither we nor Friedman and Schwartz detect an active monetary shock at the onset of the Depression, and since there is strong evidence of non-monetary shocks, the severe initial downturn was most likely largely the result of non-monetary forces. Furthermore, because our results do not provide an estimate of the size of the effect of a given monetary change, we cannot determine how much less severe the subsequent depression might have been under any particular alternative policy. 
Table 1

Basic Industrial Production Regression

Sample Period: Feb. 1948 - Dec. 1987

Dependent Variable: Percentage Change in Industrial Production

Dummy for Shift in Monetary Policy

\begin{tabular}{|c|c|c|c|c|c|}
\hline Lag & Coefficient & Standard Error & Lag & Coefficient & Standard Error \\
\hline 0 & -.0041 & .0062 & & & \\
\hline 1 & .0081 & .0062 & 1 & .2218 & .0492 \\
\hline 2 & .0014 & .0062 & 2 & .0773 & .0503 \\
\hline 3 & .0020 & .0062 & 3 & -.0294 & .0503 \\
\hline 4 & -.0004 & .0057 & 4 & .0566 & .0498 \\
\hline 5 & -.0061 & .0057 & 5 & -.0512 & .0496 \\
\hline 6 & -.0025 & .0057 & 6 & -.0937 & .0496 \\
\hline 7 & -.0071 & .0057 & 7 & .0504 & .0496 \\
\hline 8 & -.0166 & .0057 & 8 & -.0383 & .0491 \\
\hline 9 & .0030 & .0057 & 9 & -.0485 & .0491 \\
\hline 10 & -.0067 & .0057 & 10 & -.0296 & .0489 \\
\hline 11 & .0020 & .0057 & 11 & .0114 & .0485 \\
\hline 12 & .0032 & .0057 & 12 & .1497 & .0483 \\
\hline 13 & -.0055 & .0057 & 13 & -.1242 & .0483 \\
\hline 14 & -.0001 & .0058 & 14 & -.1409 & .0487 \\
\hline 15 & -.0035 & .0058 & 15 & -.0810 & .0491 \\
\hline 16 & -.0056 & .0058 & 16 & -.0714 & .0493 \\
\hline 17 & -.0025 & .0058 & 17 & .1009 & .0494 \\
\hline 18 & -.0105 & .0058 & 18 & -.0452 & .0494 \\
\hline 19 & -.0073 & .0058 & 19 & -.0085 & .0482 \\
\hline 20 & -.0116 & .0058 & 20 & -.0568 & .0473 \\
\hline 21 & .0021 & .0058 & 21 & -.0911 & .0467 \\
\hline 22 & .0009 & .0058 & 22 & .0222 & .0470 \\
\hline 23 & -.0081 & .0058 & 23 & -.0607 & .0451 \\
\hline 24 & -.0100 & .0058 & 24 & .1175 & .0434 \\
\hline 25 & .0009 & .0058 & & & \\
\hline 26 & -.0081 & .0058 & & & \\
\hline 27 & -.0021 & .0058 & & & \\
\hline 28 & -.0059 & .0058 & & & \\
\hline 29 & -.0078 & .0058 & & & \\
\hline 30 & -.0006 & .0058 & & & \\
\hline 31 & -.0055 & .0058 & & & \\
\hline 32 & -.0010 & .0058 & & & \\
\hline 33 & .0123 & .0057 & & & \\
\hline 34 & .0079 & .0057 & & & \\
\hline 35 & -.0024 & .0057 & & & \\
\hline 36 & -.0034 & .0057 & & & \\
\hline
\end{tabular}

$\mathrm{R}^{2}=.825$

S.E.E. $=.0132$

$Q(63)=53.75$
Lagged Changes in Industrial Production

Coefficients and standard errors for the constant term and monthly dummies are not reported. 
Table 2

Basic Unemployment Regression

Sample Period: Jan. 1948 - Dec. 1987

Dependent Variable: Unemployment Rate

\begin{tabular}{|c|c|c|c|c|c|}
\hline \multicolumn{3}{|c|}{ Dummy for Shift in Monetary Policy } & \multicolumn{3}{|c|}{ Lagged Unemployment Rates } \\
\hline Lag & Coefficient & Standard Error & Lag & Coefficient & Standard Error \\
\hline 0 & -.0979 & .1272 & & & \\
\hline 1 & -.1049 & .1272 & 1 & 1.0539 & .0496 \\
\hline 2 & .0460 & .1274 & 2 & .1091 & .0718 \\
\hline 3 & .0692 & .1167 & 3 & -.1685 & .0720 \\
\hline 4 & .0799 & .1166 & 4 & .0313 & .0724 \\
\hline 5 & -.0004 & .1164 & 5 & -.0140 & .0722 \\
\hline 6 & .1369 & .1161 & 6 & -.0659 & .0714 \\
\hline 7 & .0266 & .1163 & 7 & -.0371 & .0713 \\
\hline 8 & .0784 & .1160 & 8 & .0844 & .0712 \\
\hline 9 & .2989 & .1157 & 9 & -.0360 & .0704 \\
\hline 10 & -.0709 & .1162 & 10 & -.0389 & .0704 \\
\hline 11 & -.1461 & .1162 & 11 & .0881 & .0707 \\
\hline 12 & -.0692 & .1165 & 12 & .1659 & .0693 \\
\hline 13 & -.0326 & .1162 & 13 & -.2807 & .0690 \\
\hline 14 & .1691 & .1179 & 14 & -.0191 & .0705 \\
\hline 15 & .1168 & .1181 & 15 & .0113 & .0708 \\
\hline 16 & .0533 & .1182 & 16 & .0521 & .0704 \\
\hline 17 & .0162 & .1179 & 17 & .0529 & .0702 \\
\hline 18 & .0712 & .1176 & 18 & -.0967 & .0706 \\
\hline 19 & .1652 & .1175 & 19 & .1399 & .0707 \\
\hline 20 & .1053 & .1177 & 20 & -.0852 & .0711 \\
\hline 21 & .2589 & .1178 & 21 & .0100 & .0708 \\
\hline 22 & -.0212 & .1183 & 22 & .0741 & .0702 \\
\hline 23 & .0320 & .1170 & 23 & -.1261 & .0702 \\
\hline 24 & .2330 & .1170 & 24 & .0668 & .0487 \\
\hline 25 & -.1101 & .1172 & & & \\
\hline 26 & .3029 & .1173 & & & \\
\hline 27 & .2415 & .1181 & & & \\
\hline 28 & .1263 & .1190 & & & \\
\hline 29 & .1379 & .1190 & & & \\
\hline 30 & .0645 & .1184 & & & \\
\hline 31 & -.0008 & .1182 & & & \\
\hline 32 & -.0712 & .1181 & & & \\
\hline 33 & .1046 & .1169 & & & \\
\hline 34 & -.0071 & .1169 & & & \\
\hline 35 & -.0202 & .1168 & & & \\
\hline 36 & -.0824 & .1168 & & & \\
\hline
\end{tabular}

$\mathrm{R}^{2}=.981$

S.E.E. $=.267$

$\mathrm{Q}(63)=56.25$

Coefficients and standard errors for the constant term, the trend, and monthly dummies are not reported. 
Table 3

Basic Interwar Industrial Production Regression

Sample Period: Feb. 1921 - Dec. 1944

Dependent Variable: Percentage Change in Industrial Production

Dummy for Change in Monetary Policy

\begin{tabular}{|c|c|c|c|c|c|}
\hline Lag & Coefficient & Standard Error & Lag & Coefficient & Standard Error \\
\hline 0 & -.0294 & .0150 & & & \\
\hline 1 & -.0017 & .0150 & 1 & .5776 & .0680 \\
\hline 2 & .0254 & .0150 & 2 & -.0850 & .0778 \\
\hline 3 & .0018 & .0151 & 3 & -.1196 & .0775 \\
\hline 4 & .0048 & .0151 & 4 & .0110 & .0780 \\
\hline 5 & -.0066 & .0150 & 5 & .1157 & .0772 \\
\hline 6 & -.0306 & .0150 & 6 & -.1729 & .0769 \\
\hline 7 & -.0183 & .0151 & 7 & .1340 & .0779 \\
\hline 8 & -.0186 & .0151 & 8 & .0247 & .0778 \\
\hline 9 & -.0209 & .0151 & 9 & .0262 & .0765 \\
\hline 10 & -.0010 & .0151 & 10 & .0009 & .0750 \\
\hline 11 & .0082 & .0151 & 11 & .0481 & .0738 \\
\hline 12 & -.0114 & .0151 & 12 & .1407 & .0732 \\
\hline 13 & .0050 & .0137 & 13 & -.1474 & .0693 \\
\hline 14 & -.0010 & .0136 & 14 & .0789 & .0691 \\
\hline 15 & .0046 & .0135 & 15 & .0734 & .0689 \\
\hline 16 & .0008 & .0139 & 16 & -.0281 & .0695 \\
\hline 17 & -.0205 & .0139 & 17 & .0333 & .0695 \\
\hline 18 & .0434 & .0139 & 18 & -.0282 & .0686 \\
\hline 19 & .0248 & .0142 & 19 & -.0500 & .0681 \\
\hline 20 & .0149 & .0143 & 20 & .0406 & .0661 \\
\hline 21 & .0213 & .0141 & 21 & -.0641 & .0658 \\
\hline 22 & .0156 & .0142 & 22 & -.0114 & .0645 \\
\hline 23 & -.0125 & .0142 & 23 & -.0381 & .0642 \\
\hline 24 & .0118 & .0143 & 24 & .0645 & .0584 \\
\hline 25 & -.0033 & .0143 & & & \\
\hline 26 & .0171 & .0142 & & & \\
\hline 27 & -.0264 & .0142 & & & \\
\hline 28 & .0226 & .0144 & & & \\
\hline 29 & .0078 & .0142 & & & \\
\hline 30 & -.0148 & .0142 & & & \\
\hline 31 & -.0207 & .0141 & & & \\
\hline 32 & .0349 & .0142 & & & \\
\hline 33 & .0029 & .0143 & & & \\
\hline 34 & .0133 & .0141 & & & \\
\hline 35 & -.0296 & .0140 & & & \\
\hline 36 & -.0163 & .0142 & & & \\
\hline
\end{tabular}

Lagged Changes in Industrial Production

Lag Coefficient Standard Error

$\mathrm{R}^{2}=.652$

S.E.E. $=.0270$

$\mathrm{Q}(48)=18.08$

Coefficient and standard errors for the constant term and monthly dummies are not reported. 
Figure 1

Economic Activity and Monetary Shocks

Index of Industrial Production (in logarithms)

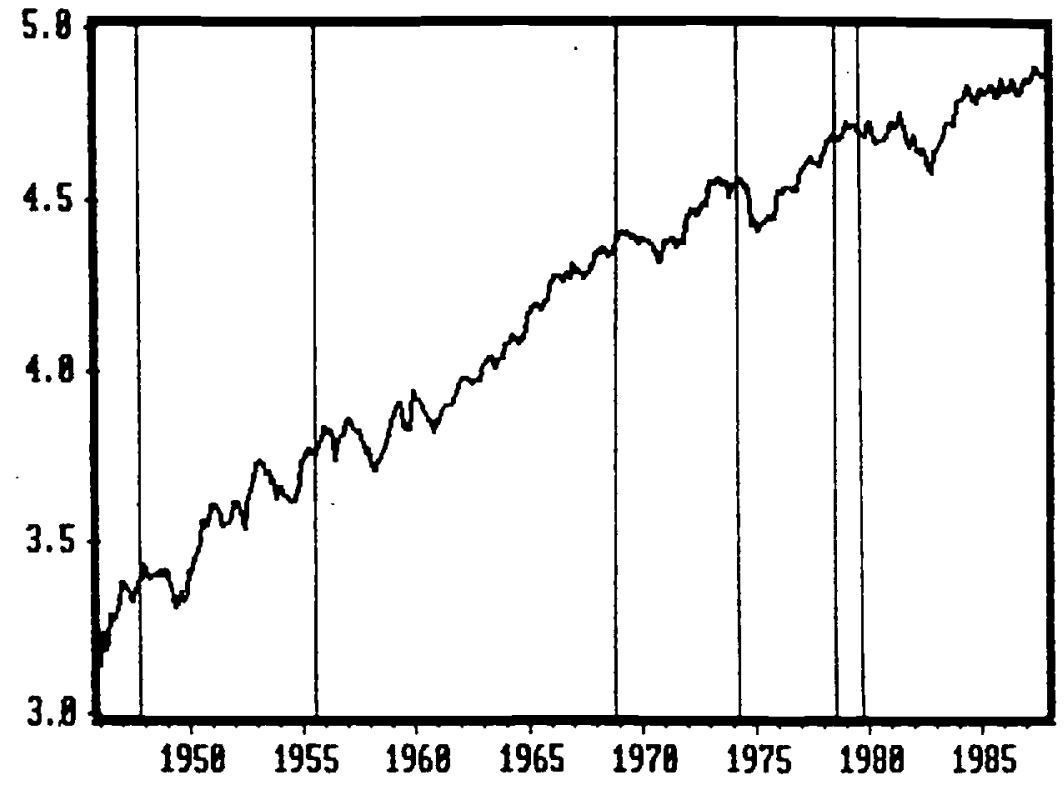

Unemployment Rate

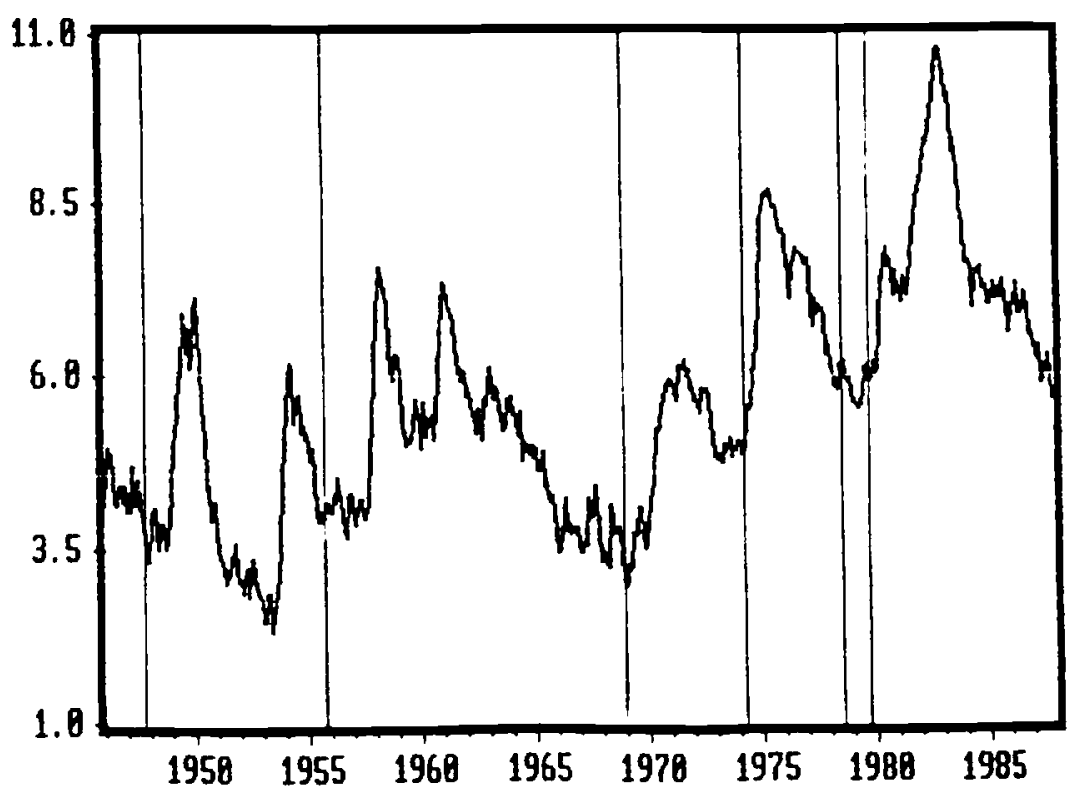

Notes: Vertical lines are drawn at the dates of monetary shocks. The actual dates are Oct. 1947, Sept. 1955, Dec. 1968, Apr. 1974, Aug. 1978, and 0ct. 1979. The source of the data is described in the text. The data have been seasonally adjusted by a regression on seasonal dummy variables. 
Figure 2

Cumulative Forecast Errors of Univariate Autoregressive Model for Industrial Production Following Monetary Shocks

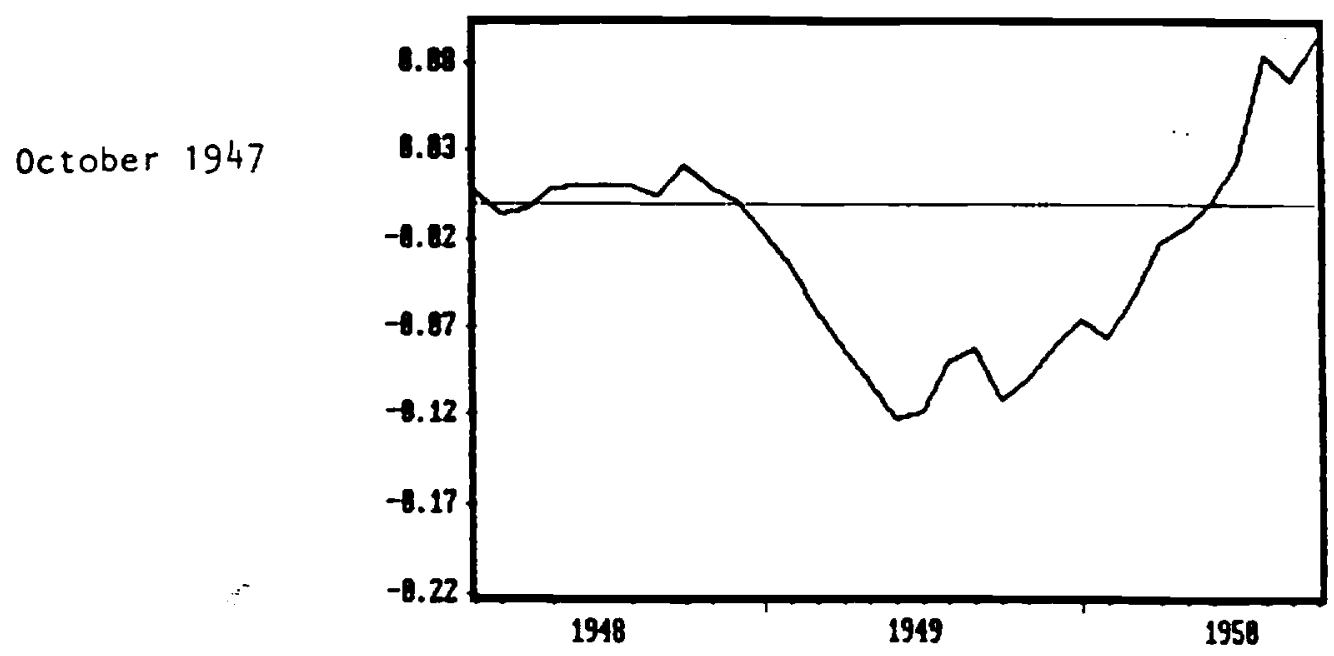

September 1955

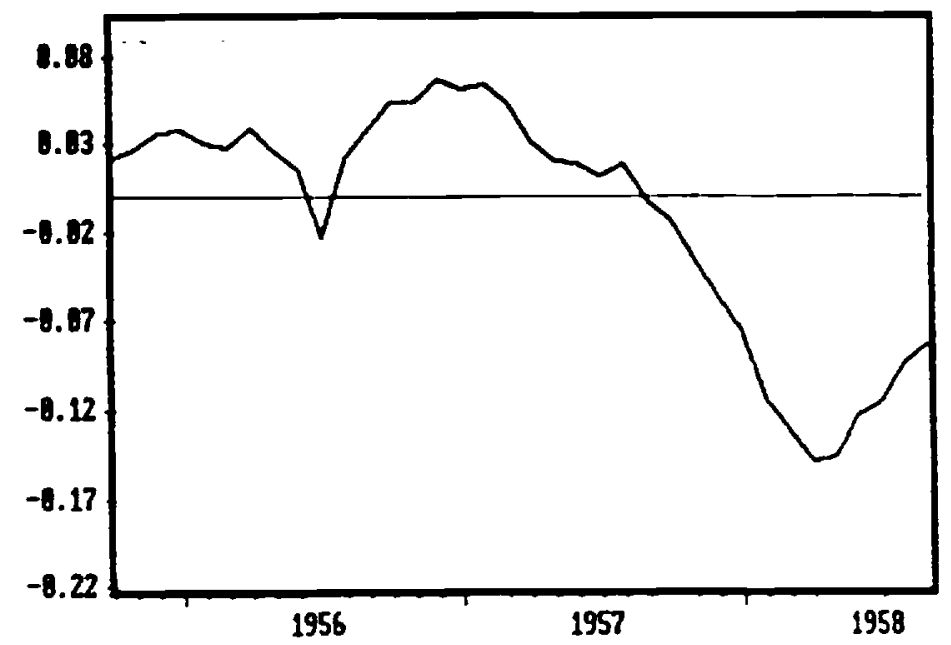

December 1968

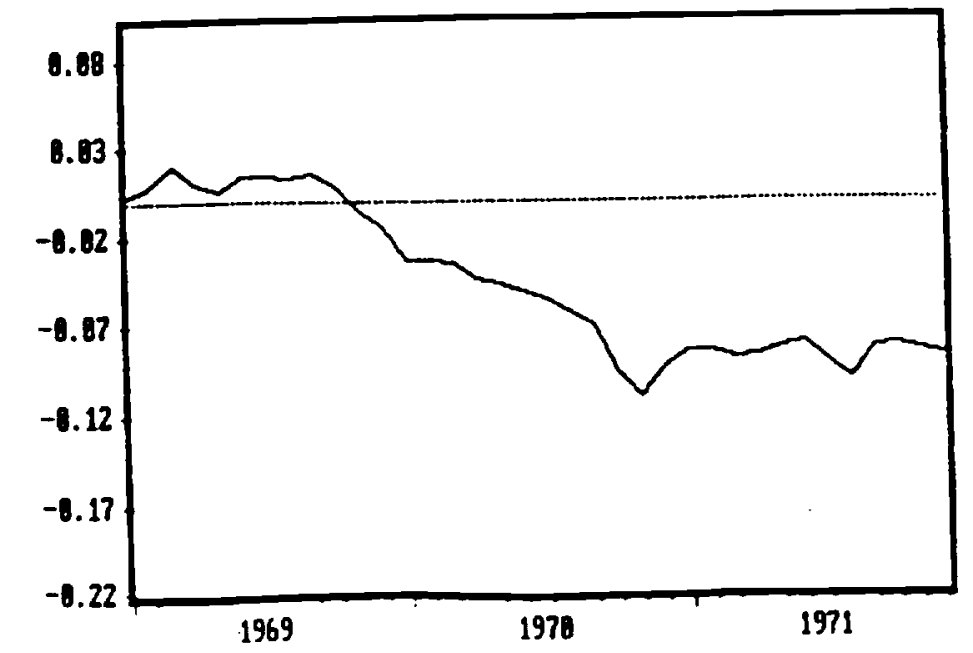


Figure 2 (continued)

April 1974

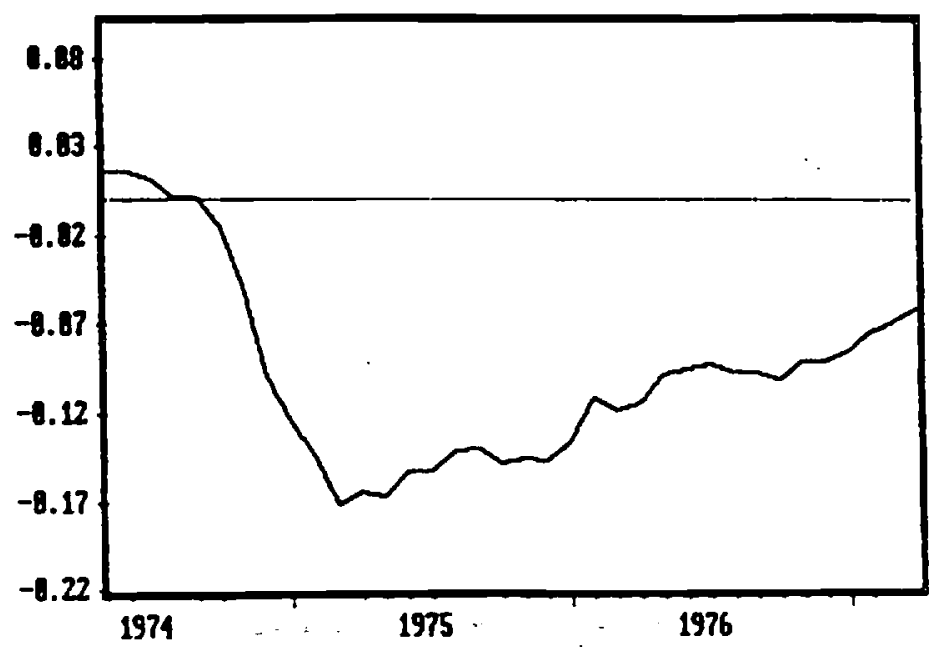

August 1978

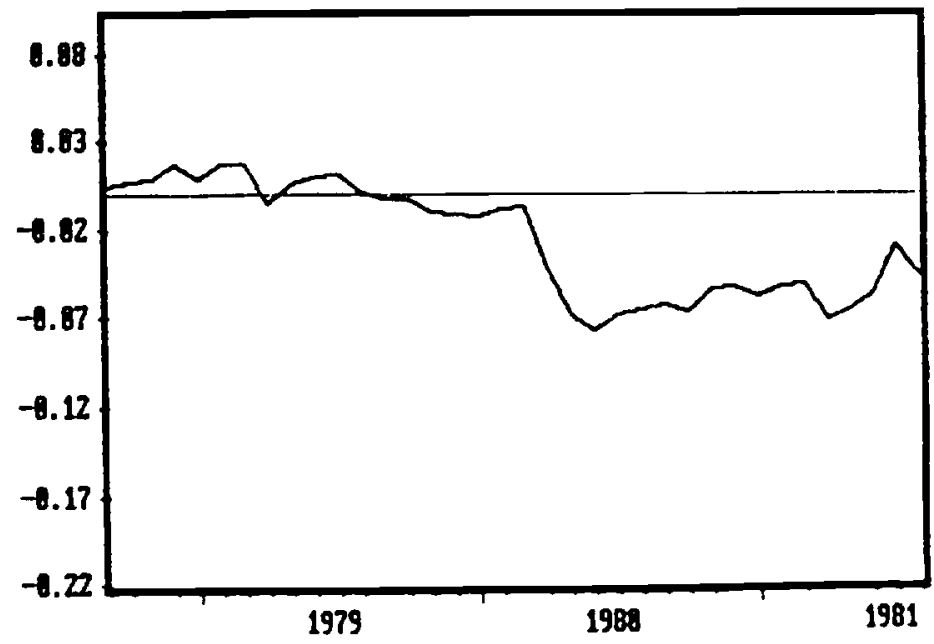

October 1979

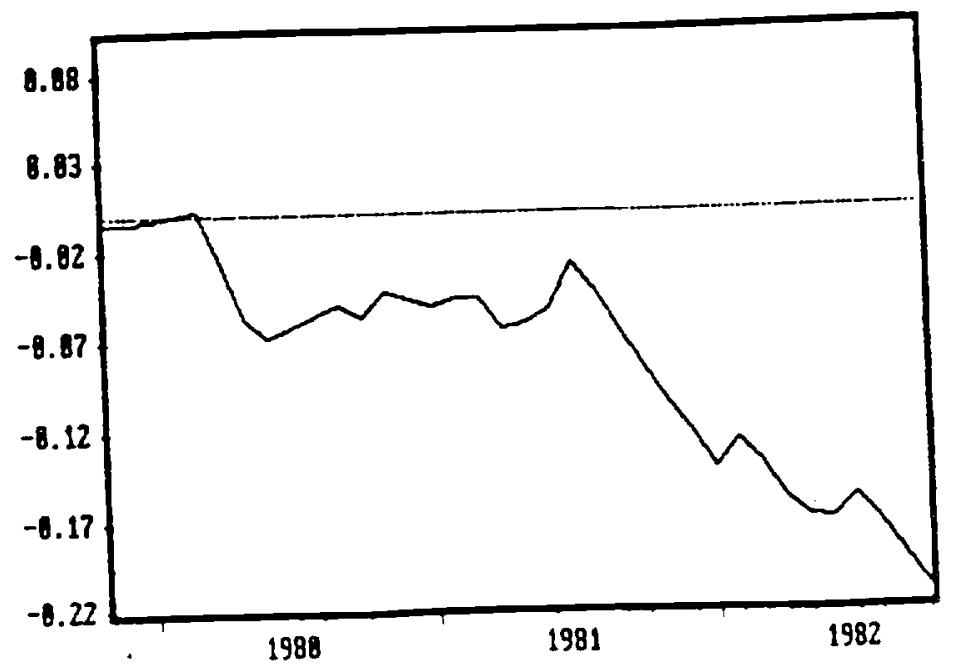


Figure 3

Forecast Errors of Univariate Autoregressive Model for the Unemployment Rate Following Monetary Shocks

October 1947

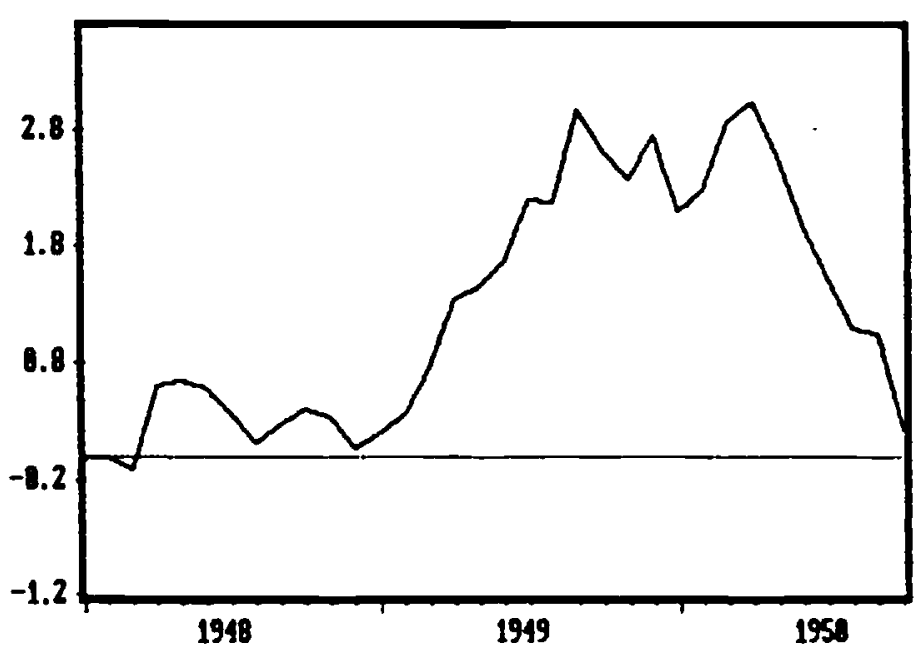

September 1955

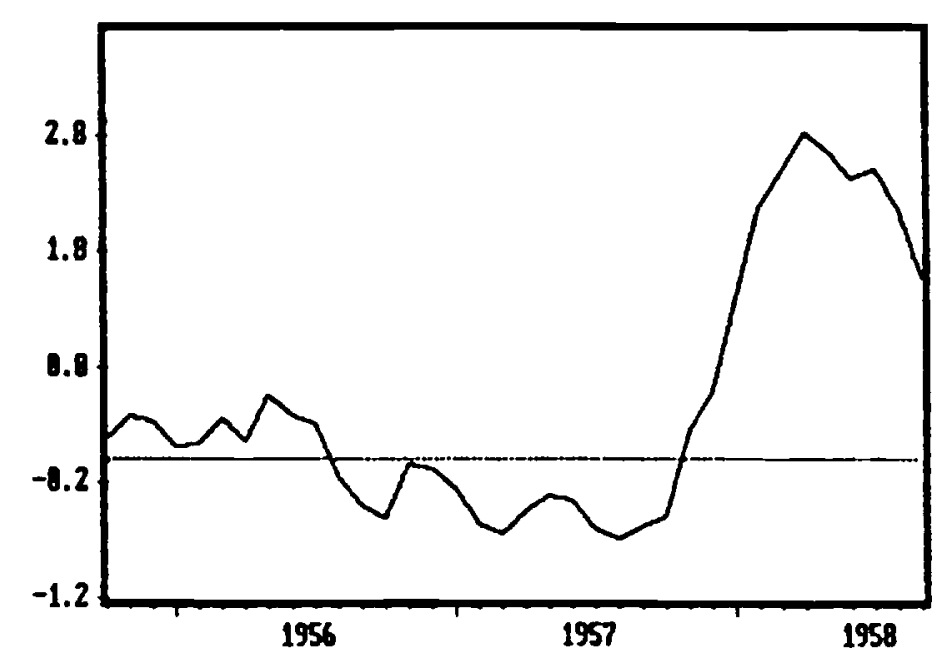

December 1968

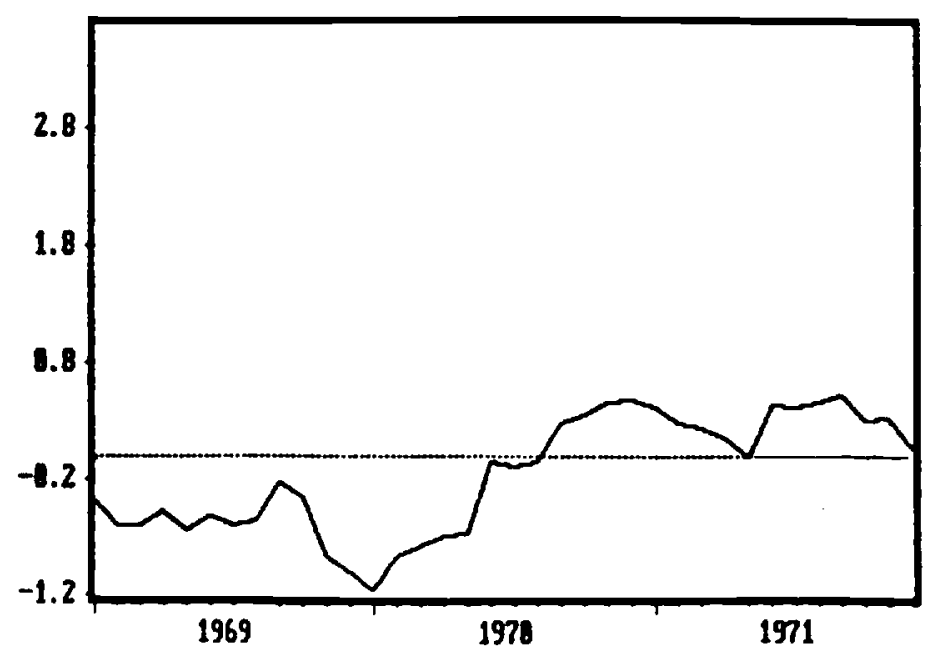


Figure 3 (continued)

April 1974

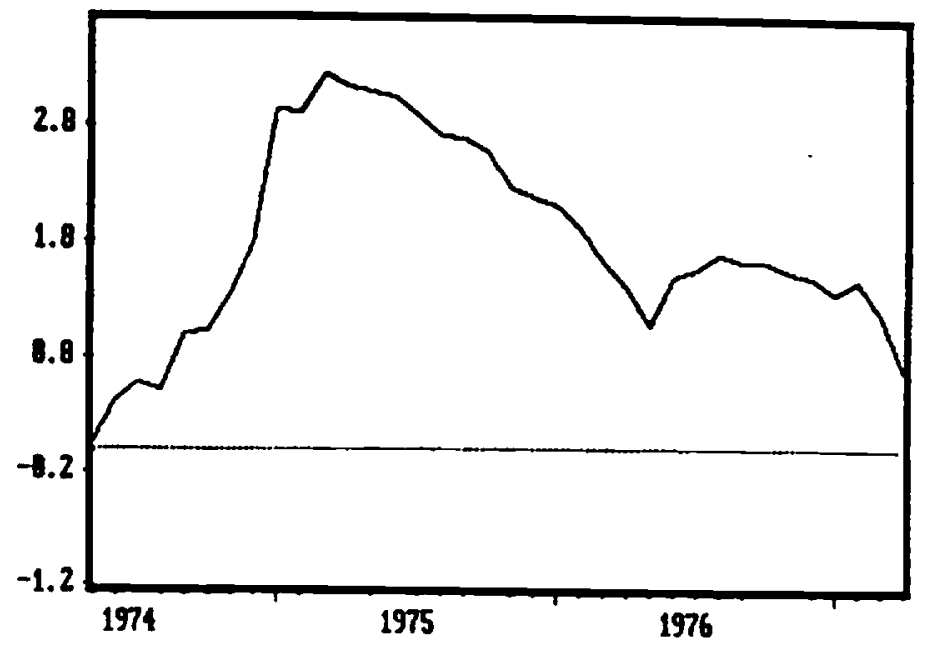

August 1978
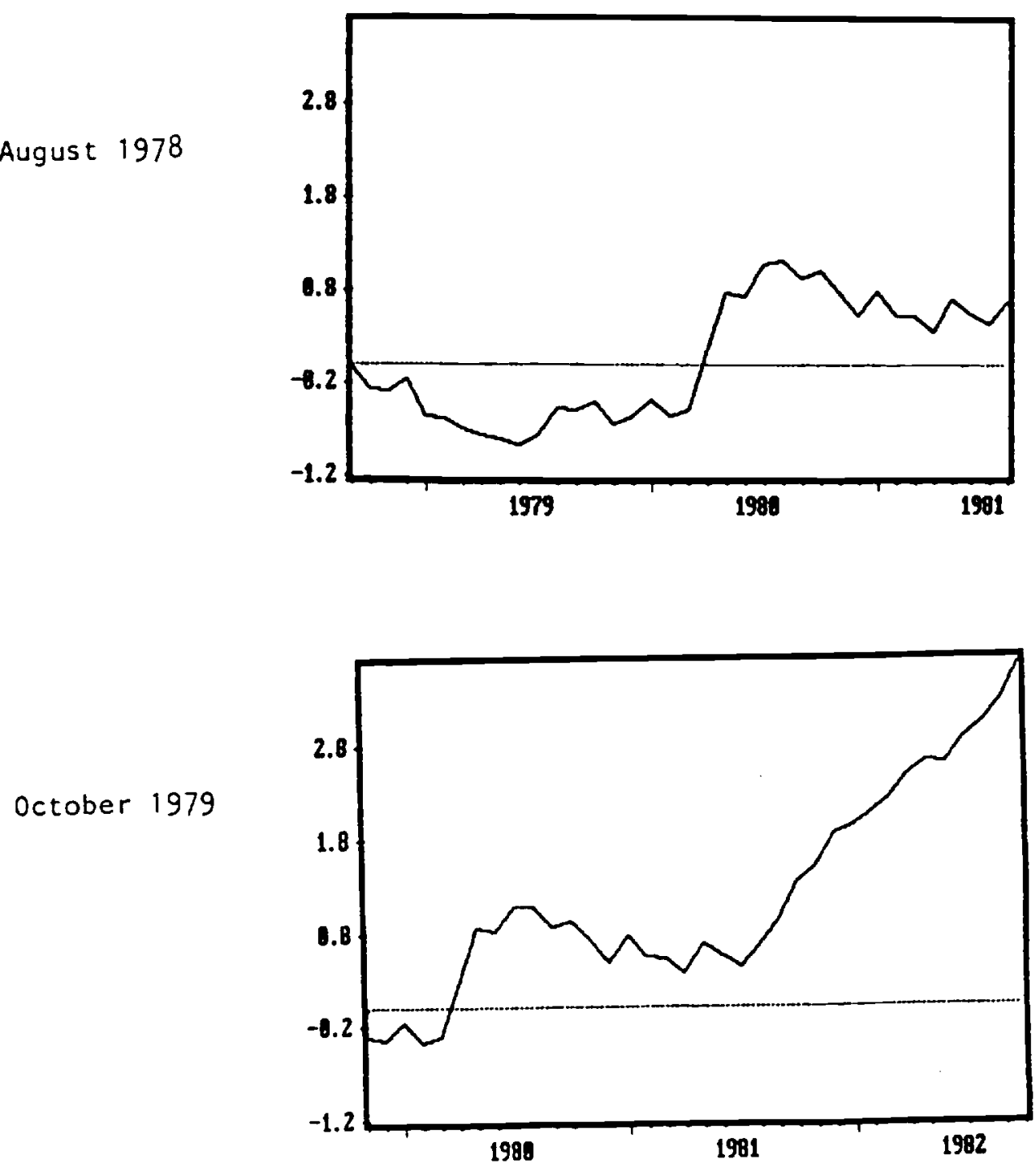
Figure 4

Impulse Response Function for

Basic Industrial Production Regression

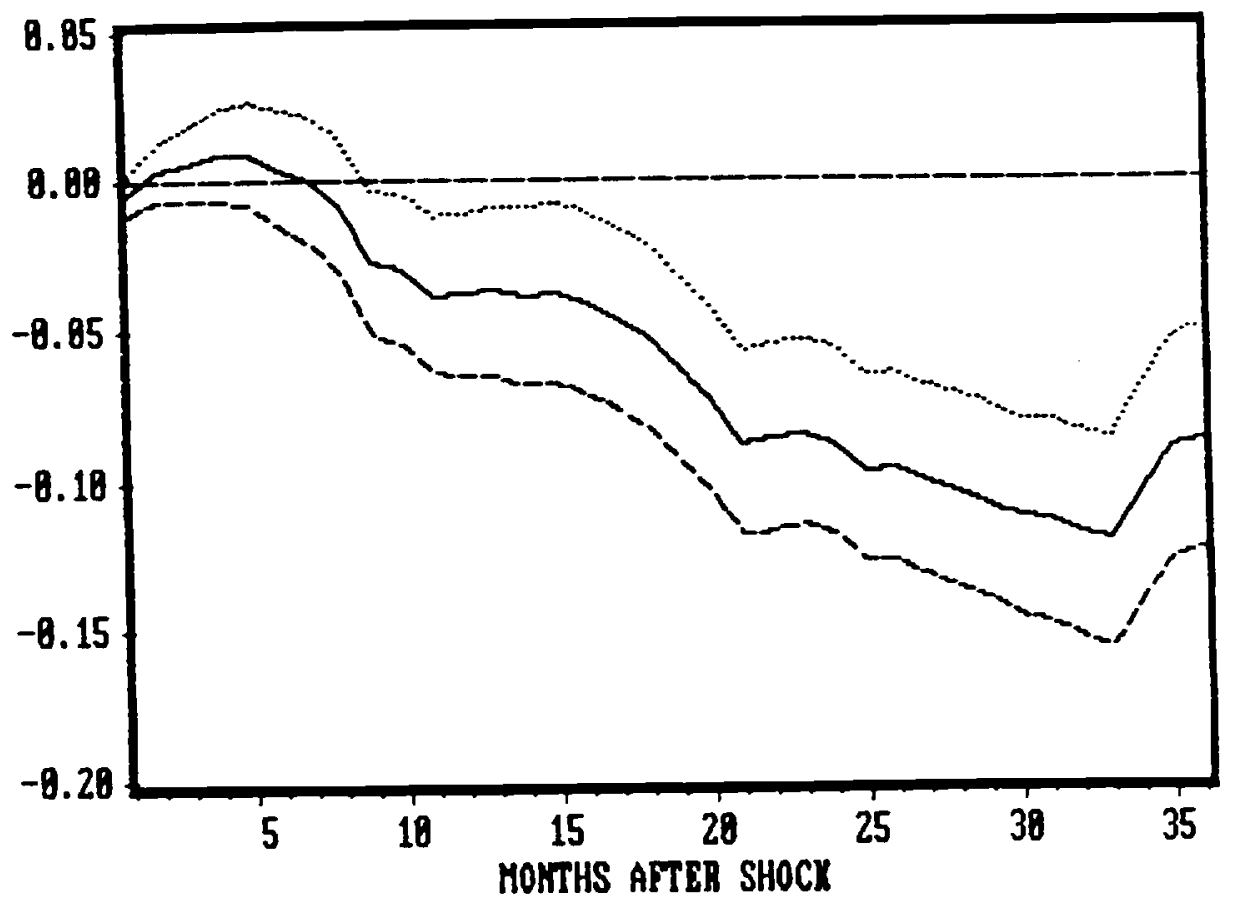

Notes: The impulse response function shows the impact of a unit shock to the monetary dummy variable. The impulse responses for the change in industrial production have been cumulated so that they reflect the movement in levels.

The coefficient estimates used to generate the impulse response function are given in Table 1.

The dashed lines show the one standard error confidence bands. 
Figure 5

Impulse Response Function for

Basic Unemployment Regression

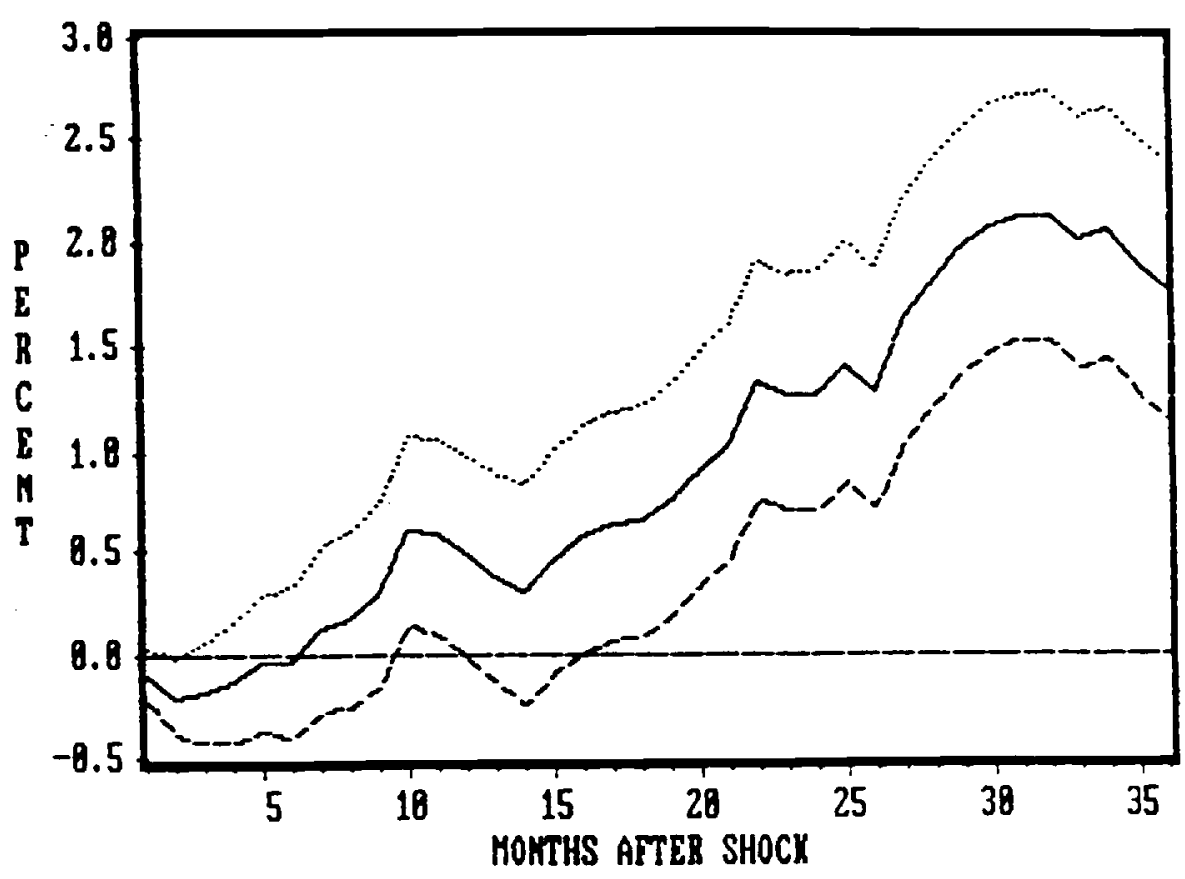

Notes: The impulse response function shows the impact of a unit shock to the monetary dummy variable

The coefficient estimates used to generate the impulse response functior are given in Table 2 .

The dashed lines show the one standard error confidence bands. 
Figure 6

Impulse Response Function for

Basic Interwar Industrial Production Regression

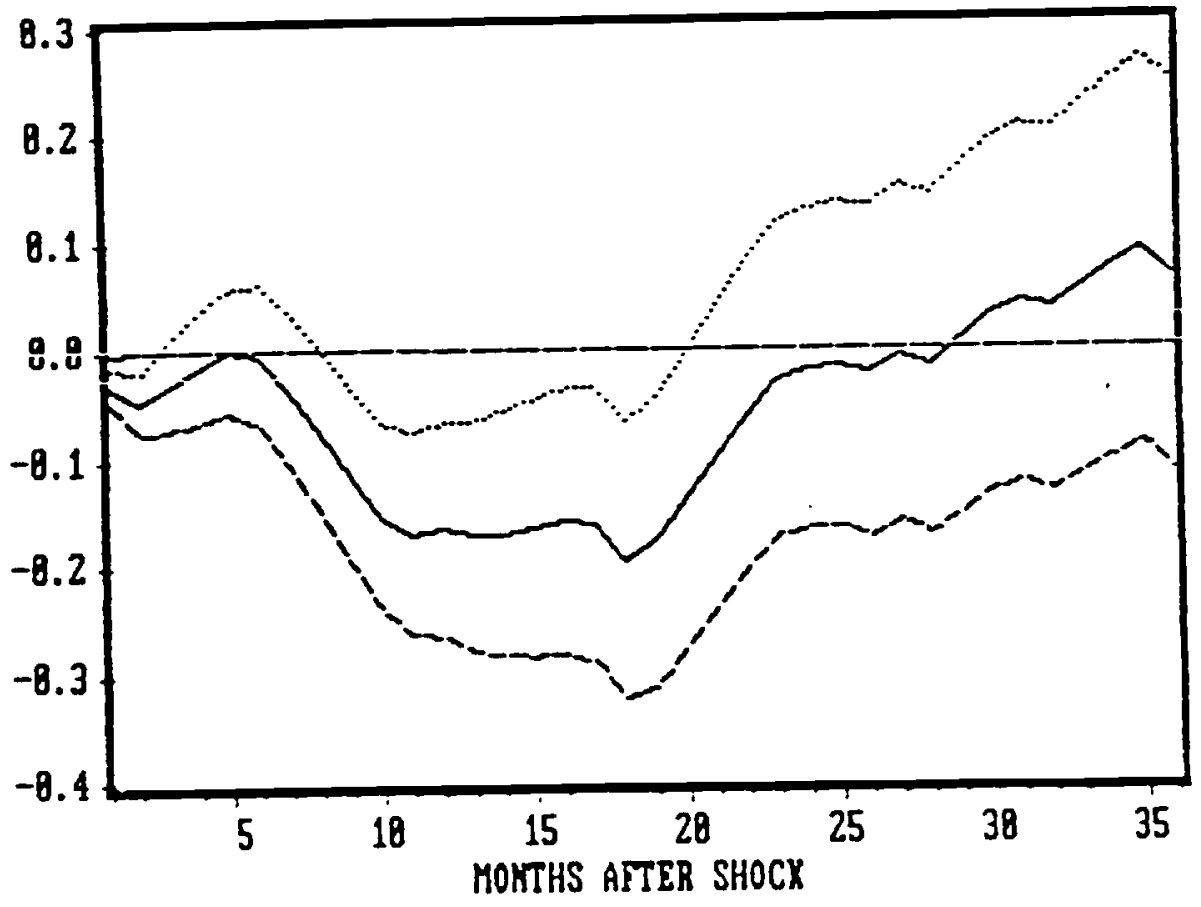

Notes: The impulse response function shows the impact of a unit shock to the monetary dummy variable. The impulse responses for the change in industrial production have been cumulated so that they reflect the movement in levels.

The coefficient estimates used to generate the impulse response function are given in Table 3 .

The dashed lines show the one standard error confidence bands. 


\section{Figure 7}

Impulse Response Function for Interwar Industrial Production Regression Using Friedman and Schwartz's Shocks

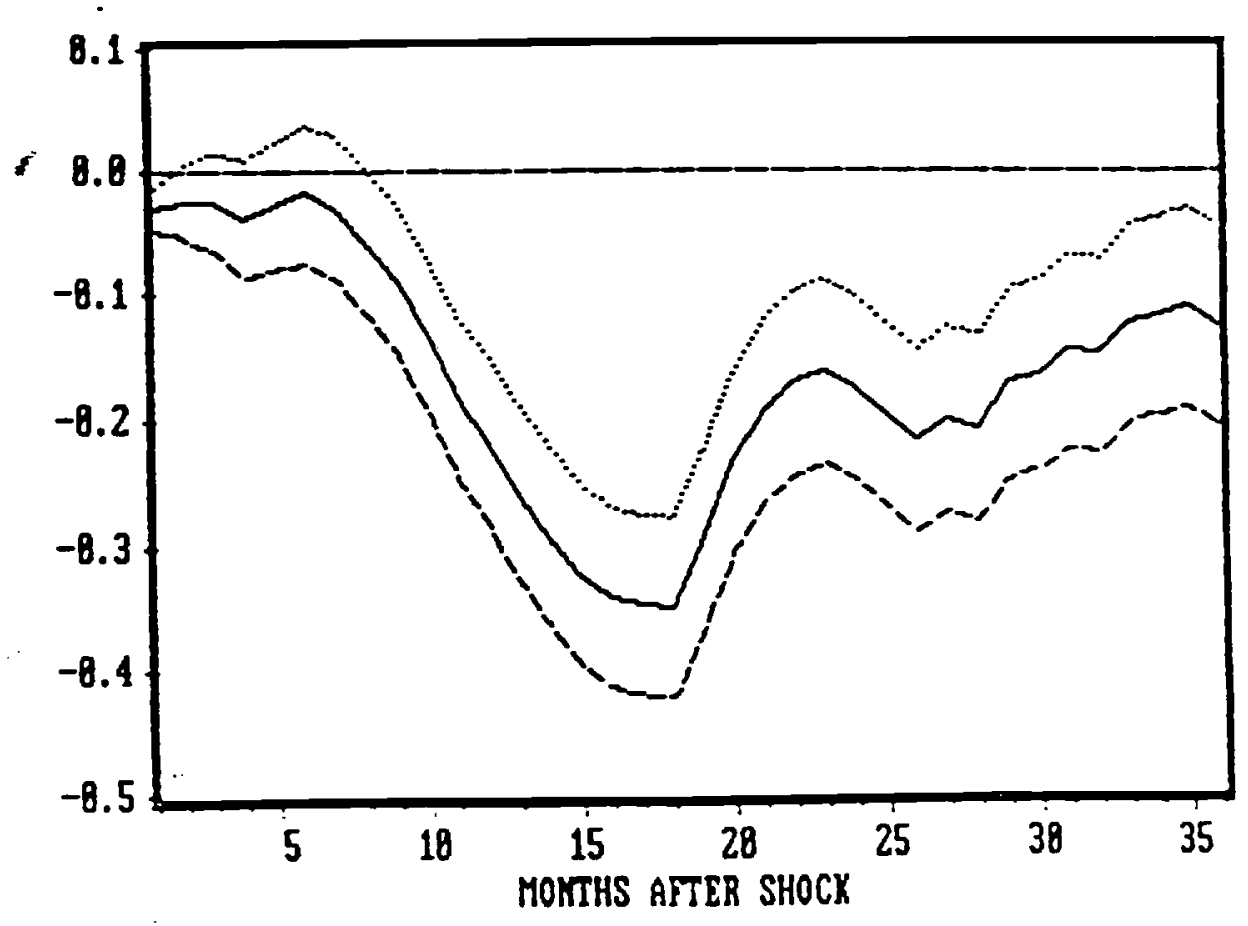

Notes: The impulse response function shows the impact of a unit shock to the monetary dummy variable. The impulse responses for the change in industrial production have been cumulated so that they reflect the movement in levels.

The dashed lines show the one standard error confidence bands. 